PALABRAS CLAVE

Crisis financiera

Globalización

Condiciones económicas

Países en desarrollo

Remesas

Comercio internacional

Comercio de productos básicos

Movimientos de capital

Indicadores económicos

América Latina

José Antonio Ocampo

Profesor de la Universidad de Columbia,

Ex Secretario Ejecutivo de la CEPAL,

Ex ministro de Hacienda y Crédito Público,

Colombia

○jao2128@columbia.edu
REVISTA CEPAL 97 - ABRIL 2009

\section{Impactos de la crisis financiera mundial sobre América Latina}

\author{
José Antonio Ocampo
}

$\mathrm{E}$

n este ensayo se sostiene que si bien se ha superado la iliquidez total que caracterizó la fase más severa de la crisis financiera desatada en septiembre de 2008, el crédito y la actividad productiva de los países industrializados se están contrayendo aceleradamente y el sistema financiero sigue descapitalizado. De los canales externos de transmisión de la crisis hacia América Latina, la disminución de las remesas es el menos importante. Los efectos negativos más generalizados serán la caída del volumen de comercio internacional y el marcado deterioro de los términos de intercambio de los productos básicos. Además, queda por delante una etapa de financiamiento externo privado muy restringido. Las economías de la región llegan a la crisis con mayor fortaleza que en el pasado, vinculada fundamentalmente al menor endeudamiento público externo y al elevado nivel de reservas internacionales, pero ella solo servirá para mitigar en parte las repercusiones de la peor coyuntura económica mundial desde la gran depresión de los años treinta. 


\section{I}

\section{Introducción}

Como se reconoce ampliamente, la economía mundial está experimentando la peor crisis financiera que se haya producido desde la gran depresión de los años treinta del siglo XX. Aunque el mundo industrializado puede evitar una contracción de la actividad productiva tan profunda como la de ese entonces, también es evidente que atraviesa por la recesión más intensa desde la Segunda Guerra Mundial. Por lo demás, los límites entre una "recesión" y una "depresión" nunca se han aclarado del todo. La crisis está llegando a todos los rincones del planeta. Dado el papel de China como bastión del dinamismo económico mundial en las últimas décadas, la contracción de sus exportaciones en noviembre y diciembre de 2008 y el virtual estancamiento de la economía durante el último trimestre del mismo año son la constatación más evidente de que la crisis mundial es muy profunda.

En el caso de América Latina, la coyuntura marcadamente favorable del período 2003-2007, basada en una combinación inusual de auge financiero, bonanza excepcional de precios de los productos básicos y nivel elevado de remesas de los trabajadores migrantes, también ha llegado a su fin. Ya a lo largo de 2008 varias economías de la región experimentaron una desaceleración importante, entre ellas Colombia, México, República Bolivariana de Venezuela y casi todas las economías más pequeñas de Centroamérica y el Caribe. Como se verá, la abundancia de financiamiento se redujo desde el tercer trimestre de 2007, coincidiendo con la primera fase de la crisis financiera en los Estados Unidos. A su vez, a mediados de 2008 se inició la baja de precios de los productos básicos. Pero fue el colapso financiero mundial de mediados de septiembre de 2008 lo que desencadenó los cambios más profundos, al paralizar el crédito, elevar marcadamente los márgenes de riesgo, convertir la caída de los precios de los productos básicos en un desplome y desencadenar una profunda recesión en el mundo industrializado. Incluso las economías latinoamericanas que habían mantenido un alto y aún

$\square$ El autor agradece la colaboración de María Paula Carvajal en la elaboración de este documento. El ensayo se realizó para el proyecto "Estado, democracia y mercado: informe regional sobre la democracia en América Latina" del Programa de las Naciones Unidas para el Desarrollo (PNUD). creciente dinamismo hasta el tercer trimestre de 2008, como Brasil y Perú, se estrellaron contra la pared.

Visto en retrospectiva, lo peculiar del mundo en desarrollo fue su relativa capacidad de aislarse de la primera fase de la crisis, gracias a la renovada bonanza de precios de los productos básicos, la relativa seguridad que representaba para los capitales externos el altísimo nivel de las reservas internacionales y el dinamismo persistente de las grandes economías asiáticas. Esto dio lugar a la tesis, difundida entre otros por el Fondo Monetario Internacional (FMI), de que el mundo en desarrollo se "desacoplaría" de las tendencias adversas del mundo industrializado. Pero, utilizando la terminología de Calvo (2008), ese "veranillo" fue sucedido por el "vendaval" que desencadenó la crisis financiera mundial de septiembre de 2008. Entonces, se hizo evidente que la tesis del desacople no era más que una ficción.

En este ensayo se analizan los efectos de la crisis internacional en América Latina. Después de esta introducción, la segunda sección incluye unas reflexiones sobre la crisis financiera de los Estados Unidos. En la tercera se consideran los tres canales externos de transmisión de la crisis, vinculados a la inversión de los mecanismos que generaron el auge precedente. La cuarta contiene algunas consideraciones sobre la vulnerabilidad de los países de la región y se termina con una breve sección de conclusiones.

Como se hará evidente en la segunda sección, al momento de finalizar la redacción de este ensayo (enero de 2009) la situación internacional continuaba siendo muy fluida. Debido a su severa descapitalización, el sector financiero mundial no había encontrado un punto de estabilidad y el crédito seguía en fase de contracción, mientras que la actividad económica y el comercio internacional decrecían a un ritmo acelerado. Lo que esto indica es que todavía se desconocía la intensidad y duración de la crisis. Al mismo tiempo, se estaban poniendo en marcha nuevos paquetes macroeconómicos, entre ellos la segunda fase del plan de rescate financiero de los Estados Unidos, el programa fiscal anunciado por la administración Obama y el nuevo paquete de rescate financiero anunciado por el gobierno británico. En este sentido, muchas de las reflexiones contenidas en este ensayo están sujetas a futuras contingencias. 


\section{II}

\section{La crisis financiera mundial}

En enero de 2009 se había cumplido ya un año y medio desde la crisis que desencadenó la titularización de las hipotecas de baja calidad en Estados Unidos. Además, habían pasado cuatro meses desde la fatídica semana que se inició el domingo 14 de septiembre de 2008 con la quiebra de Lehman Brothers, uno de los cinco grandes bancos de inversión estadounidenses y el rescate de otro de ellos, Merrill Lynch, que pasó a ser una subsidiaria del Bank of America; Bear Stearns, que había recibido ayuda en marzo, entró en proceso de fusión con J.P. Morgan Chase. La semana continuó con el rescate de la principal empresa de seguros, American Insurance Group (AIG), la venta forzosa de los activos del principal banco de ahorro y crédito - Washington Mutual-y de uno de los bancos comerciales más grandes, Wachovia. Muchos otros de menor tamaño habían venido quebrando y han seguido haciéndolo desde entonces. Además, algunos bancos de inversión aún independientes como Goldman Sachs y Morgan Stanley —el grupo financiero japonés Mitsubishi UfJ adquiriría en octubre una quinta parte de la propiedad del segundo ellos- se convirtieron en sociedades de inversión (holdings) bancarias, pasando de esta manera a la supervisión de la Reserva Federal. El miércoles 17 y el jueves 18 de septiembre el sistema financiero de los Estados Unidos estuvo a punto de sufrir un colapso total y se inició un período que vino a llamarse de "congelamiento" del crédito, que en su momento más crítico implicó la paralización del crédito interbancario y de la emisión de valores comerciales de corto plazo. Durante esa semana se desencadenó también una secuencia de quiebras de los bancos europeos, que todavía no se detiene. Cabe señalar que algunos bancos británicos habían enfrentado dificultades desde antes.

Como lo ha señalado el gran historiador económico Charles Kindleberger (Kindleberger y Aliber, 2005), la frecuencia de las crisis financieras es un hecho recurrente en la historia del capitalismo. Además, desde los años sesenta se ha acentuado el surgimiento de perturbaciones financieras de distinto tipo, coincidiendo con diversos procesos de liberalización económica mundial (Bordo y otros, 2001). En el caso de los Estados Unidos, esta es la tercera crisis bancaria de las últimas décadas. La primera fue la crisis latinoamericana de la deuda, que fue hábilmente manejada a fin de que América Latina pagara los costos e incluso no quedara registrada como lo que también fue, esto es, una quiebra de los principales bancos estadounidenses. La segunda fue la crisis del sistema de ahorro y crédito de los Estados Unidos a fines de los años ochenta y la tercera, la que se está experimentando en la actualidad. A ello podrían agregarse los grandes colapsos bursátiles, incluidos el "lunes negro" de octubre de 1987 y el estallido de la burbuja de títulos tecnológicos de comienzos del actual decenio, así como tres episodios de marcada caída del dólar, el último de los cuales ya se venía registrando hasta que la crisis de septiembre invirtió el fenómeno de manera transitoria.

Básicamente, la frecuencia de las crisis obedece a la incapacidad de los sistemas financieros de autorregularse, uno de cuyos corolarios es que las medidas de liberalización financiera contienen el germen de ellas. El problema fundamental, como lo señalara Minsky (1982) hace un cuarto de siglo, es que a medida que avanzan las bonanzas financieras tiende a aumentar la confianza, lo cual conduce a que los agentes financieros tomen posiciones cada vez más riesgosas en el sentido de que las obligaciones financieras superan sus ingresos corrientes o, visto desde la perspectiva de las hojas de balance, que aumenta el endeudamiento en relación con el capital (mayor apalancamiento). La lógica de este modo de operar durante los períodos de auge es incuestionable, porque permite obtener utilidades con poco capital, gracias a la inflación de precios de los activos que se autogenera. La bonanza termina, por lo tanto, con un nivel de endeudamiento excesivo de todos los agentes y escasa capitalización de las entidades financieras, lo que siembra la semilla de las quiebras tanto de los deudores como de los intermediarios financieros. Aunque esta lógica es recurrente, sin duda la crisis actual es la "prueba maestra" de que los mercados financieros, aun los más sofisticados, son incapaces de autorregularse.

Ante el colapso que experimentaron muchos países en desarrollo a partir de la secuencia de las crisis asiática, rusa y latinoamericana de fines del siglo pasado, la ortodoxia económica terminó por aceptar que las medidas de liberalización financiera deben acompañarse de mejor regulación y una supervisión prudencial - lo que ya había ocurrido en varios países de América Latina tras la crisis de la deuda de los años ochenta-. Pero esta 
recomendación no se aplicó al centro del capitalismo financiero mundial, en el que continuó el proceso de desregulación. Entre otras cosas, este se tradujo en la eliminación definitiva, en 1999, de las fronteras entre la banca de inversión y la banca comercial que se habían establecido en los años treinta del siglo XX y en la liberalización, en 2004, de los requisitos de capital de la banca de inversión, lo cual la condujo a duplicar los niveles de apalancamiento en los años siguientes. Además, no hubo regulación alguna respecto de "innovaciones financieras" como las hipotecas de baja calidad, su titularización o la proliferación de derivados financieros, entre los cuales destacan los nuevos seguros de crédito a los que podría denominarse "permutas del riesgo de incumplimiento del deudor" (credit default swaps). Tampoco hubo un intento por frenar, mediante la fiscalización, la multiplicación de los activos financieros no incluidos en el balance de las entidades más reguladas (los bancos) y tampoco se aplicó regulación alguna a nuevos intermediarios como los fondos de inversión alternativa (hedge funds).

A lo anterior se agrega que muchos agentes no bancarios se fueron especializando en la transformación de los plazos —esto es, captar recursos a corto plazo mediante emisiones de bonos para prestarlos o invertirlos a largo plazo-, generando una especie de "sistema bancario en la sombra". Esta es una función que tradicionalmente se ha asignado a los bancos comerciales y que se torna muy problemática durante las crisis. Una de sus manifestaciones más desastrosas es el retiro de depósitos desde los bancos, un problema que si bien no ha estado enteramente ausente durante la crisis actual, ha tendido a desaparecer mediante la difusión de los seguros sobre depósitos. Sin embargo, como los agentes no bancarios no tienen acceso a estos seguros - y puesto que su alcance es limitado_-, el problema se ha manifestado ahora en retiros masivos desde los fondos mutuos, de inversión alternativa y otros.

Las respuestas iniciales de las autoridades económicas giraron en torno al mejoramiento de las líneas de provisión de liquidez y la reducción de las tasas de intervención de los bancos centrales, es decir, al desempeño eficaz de su función de prestamistas de última instancia. Las primeras medidas de acceso a las líneas de redescuento de la Reserva Federal se anunciaron a mediados de agosto de 2007, poco después de iniciado el colapso del mercado de títulos financieros respaldados por hipotecas (en el gráfico 1 se aprecia uno de los aspectos de ese colapso, que tuvo lugar en el mercado de

GRÁFICO 1

Estados Unidos: valores comerciales en circulación

(En miles de millones de dólares)

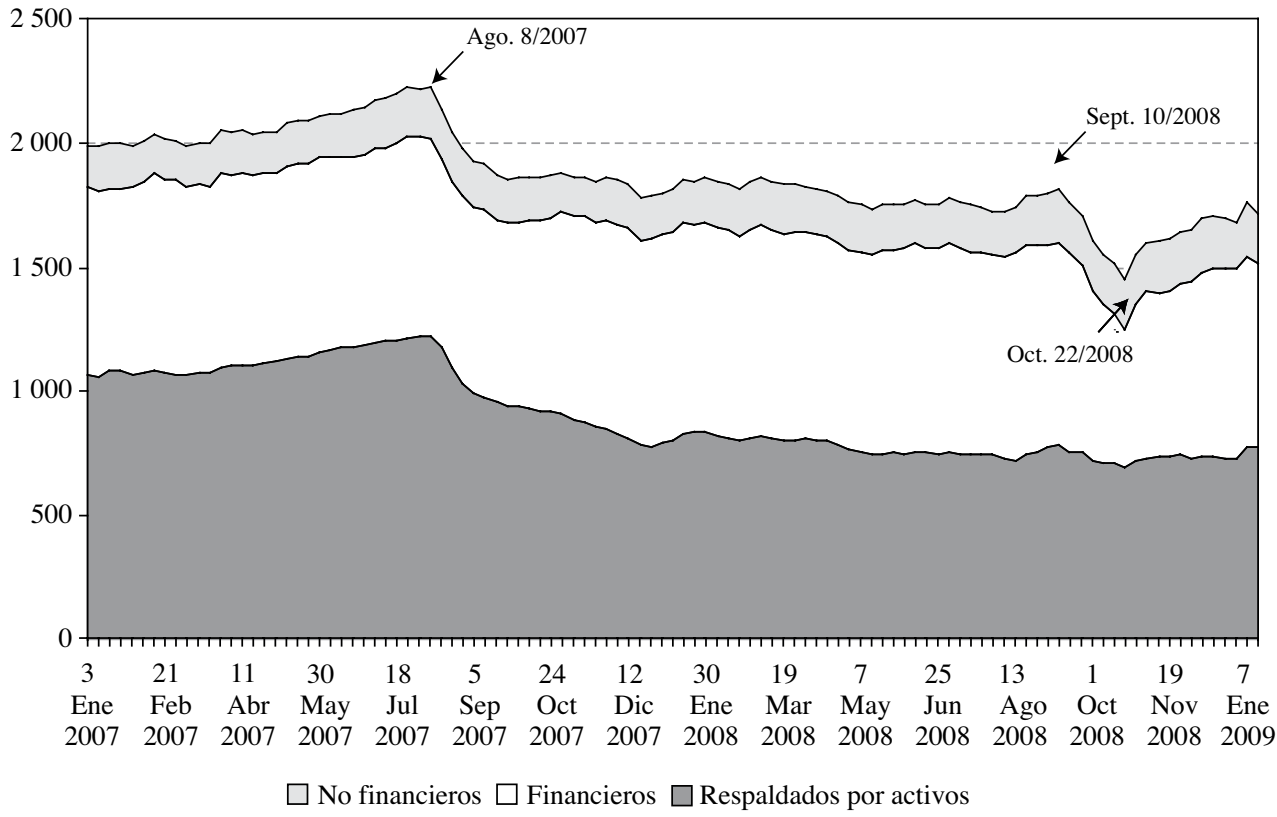

Fuente: Sistema de la Reserva Federal, FRB__CP-1 Series, Washington, D.C. 
valores comerciales titularizados). En septiembre de 2007, redujo por primera vez las tasas de intervención. Entre los principales bancos centrales del mundo, la Reserva Federal ha sido agresiva en ambos campos, seguida por el Banco de Inglaterra, en tanto que el Banco Central Europeo ha tenido una actitud mucho más conservadora. Las líneas de crédito se multiplicaron a lo largo del tiempo y pudieron utilizarlas una serie de intermediarios que jamás habían tenido acceso a ellas. El primer paso en esta dirección se tomó en Estados Unidos en marzo de 2008, a raíz de la quiebra de Bear Stearns, cuando se permitió que los bancos de inversión accedieran a líneas específicas de crédito de la Reserva Federal.

Durante la primera fase de la crisis, que se extendió desde mediados de agosto de 2007 hasta la quiebra de Bear Stearns en marzo de 2008, se produjo un marcado deterioro del mercado de valores respaldados por hipotecas. El hecho de que muchos de estos títulos se encontraban en poder de intermediarios financieros, incluso sin figurar en el balance, contribuyó a generar una desconfianza recíproca respecto de la calidad de sus carteras, que con el tiempo se convertiría en el elemento más decisivo de la crisis. Inicialmente, el uso de las líneas de crédito creadas por la Reserva Federal fue moderado, pero se aceleró a partir de marzo de
2008, fecha que por lo tanto puede considerarse como el comienzo de una segunda fase de la crisis. Al mismo tiempo, se redujo el monto de bonos de la deuda pública que tenía en su poder y no había puesto a disposición de agentes privados en calidad de préstamos, lo que le permitió mantener el tamaño total de su cartera (véase el cuadro 1). La reducción de las tasas de intervención, que hasta marzo de 2008 fue muy pronunciada (entre tres y cuatro puntos porcentuales), se transmitió a los bonos del Tesoro a corto plazo, el mercado interbancario y las tasas de depósito y crédito del sistema bancario, pero las tasas del mercado de capitales (bonos empresariales y de los gobiernos estaduales y locales) y de las hipotecas se mantuvieron prácticamente inalteradas (véase el cuadro 2).

La magnitud del colapso de mediados de septiembre 2008, en que se inicia la tercera fase de la crisis, tomó por sorpresa a las autoridades y al propio mercado. La paralización del crédito llevó al banco central a tomar medidas totalmente inesperadas, incluida la decisión de comprar valores comerciales por intermedio de una compañía de responsabilidad limitada —en realidad, un fondo administrado por el Banco de la Reserva Federal de Nueva York - cuyos activos están respaldados por el gobierno federal. Este fue el mecanismo que se había

\begin{tabular}{|c|c|c|c|c|c|c|}
\hline Semana terminada & $\begin{array}{c}\text { Agosto } 8 \\
2007\end{array}$ & $\begin{array}{c}\text { Enero } 2 \\
2008\end{array}$ & $\begin{array}{c}\text { Marzo } 12 \\
2008\end{array}$ & $\begin{array}{c}\text { Sept. } 10 \\
2008\end{array}$ & $\begin{array}{c}\text { Nov. } 12 \\
2008\end{array}$ & $\begin{array}{c}\text { Enero } 28 \\
2009\end{array}$ \\
\hline Total créditos & 850,6 & 891,7 & 869,2 & 888,3 & 2198,2 & 1989,9 \\
\hline Títulos federales en su poder, sin prestar & 787,3 & 724,1 & 697,5 & 361,7 & 271,2 & 376,2 \\
\hline Créditos y cartera adquirida al sector privado & 22,3 & 102,0 & 130,5 & 428,1 & 1313,4 & 1105,4 \\
\hline Líneas tradicionales ${ }^{\mathrm{a}}$ & 22,3 & 62,0 & 70,5 & 132,9 & 193,8 & 89,5 \\
\hline Subasta de crédito & & 40,0 & 60,0 & 150,0 & 415,3 & 415,9 \\
\hline Préstamo de títulos federales & & & & 115,9 & 200,0 & 125,1 \\
\hline Facilidades para bancos de inversión & & & & & 64,9 & 32,1 \\
\hline Valores comerciales respaldados con activos & & & & & 80,2 & 14,6 \\
\hline Créditos al AIG & & & & & & 38,3 \\
\hline Otros & & & & & 82,3 & 0,0 \\
\hline Cartera neta de valores comerciales en compañías & & & & & & \\
\hline de responsabilidad limitada & & & & & 249,9 & 316,2 \\
\hline Cartera neta de Maiden Lane ${ }^{\mathrm{b}}$ & & & & 29,3 & 26,9 & 27,0 \\
\hline Cartera neta de Maiden Lane II y III ${ }^{\mathrm{c}}$ & & & & & & 46,7 \\
\hline Activos denominados en moneda extranjera y otros & 41,8 & 66,6 & 42,4 & 99,6 & 615,0 & 510,3 \\
\hline (Canjes con bancos centrales) & & & & & & 465,9 \\
\hline Flotante & $-0,9$ & $-1,0$ & $-1,2$ & $-1,0$ & $-1,5$ & $-2,0$ \\
\hline
\end{tabular}

Fuente: Sistema de la Reserva Federal, Federal Reserve Statistical Release, H.4.1, Washington, D.C., 2009.

a Operaciones con pacto de recompra, líneas primaria, secundaria y estacional, y préstamos de bonos del Tesoro a un día.

b Compañía de responsabilidad limitada creada para administrar la cartera de Bear Stearns.

c Compañía de responsabilidad limitada creada para administrar la cartera del AIG. 


\section{Estados Unidos: tasas de interés seleccionadas}

\begin{tabular}{|c|c|c|c|c|c|c|}
\hline Semana terminada & $\begin{array}{c}\text { Ago. } 10 \\
2007\end{array}$ & $\begin{array}{c}\text { Marzo } 28 \\
2008\end{array}$ & $\begin{array}{l}\text { Sept. } 12 \\
2008\end{array}$ & $\begin{array}{c}\text { Oct. } 31 \\
2008\end{array}$ & $\begin{array}{c}\text { Enero } 16 \\
2009\end{array}$ & $\begin{array}{c}\text { Enero } 23 \\
2009\end{array}$ \\
\hline \multicolumn{7}{|l|}{ Tasas de intervención } \\
\hline Fondos federales & 5,25 & 2,18 & 1,99 & 0,82 & 0,10 & 0,20 \\
\hline Redescuento & 6,25 & 2,50 & 2,25 & 1,68 & 0,50 & 0,50 \\
\hline Interbancaria (Libor) & 5,43 & 2,67 & 2,82 & $4,70^{*}$ & 1,11 & 1,14 \\
\hline \multicolumn{7}{|l|}{ Bonos del Tesoro } \\
\hline 1 mes & 4,82 & 1,22 & 1,53 & 0,28 & 0,04 & 0,03 \\
\hline 10 años & 4,79 & 3,52 & 3,66 & 3,92 & 2,30 & 2,56 \\
\hline \multicolumn{7}{|l|}{ Certificados de depósito, $3 \mathrm{~m}$. } \\
\hline Préstamos preferenciales & 8,25 & 5,25 & 5,00 & 4,43 & 3,25 & 3,25 \\
\hline \multicolumn{7}{|l|}{ Bonos empresariales } \\
\hline AAA & 5,78 & 5,51 & 5,46 & 6,42 & 4,89 & 5,10 \\
\hline BAA & 6,66 & 6,93 & 7,05 & 9,49 & 7,97 & 8,15 \\
\hline Bonos gobiernos estaduales y locales & 4,59 & 4,96 & 4,54 & 5,35 & 4,80 & 5,13 \\
\hline Hipotecas convencionales & 6.59 & 5,85 & 5,93 & 6,46 & 4,96 & 5,12 \\
\hline
\end{tabular}

Fuente: Sistema de la Reserva Federal, Federal Reserve Statistical Release, H.15, Washington, D.C., 1997.

* Semana terminada el 15 de septiembre de 2008.

diseñado desde el mes de marzo para manejar la cartera de Bear Stearns y que se utilizaría para administrar la de AIG. Estas medidas representaron un cambio de enfoque en la política: de respaldar la liquidez del sistema se pasó a reactivar el crédito. Gradualmente, este objetivo incluyó la reducción de las tasas de interés de los créditos comerciales (destinados a la compra de vehículos, educación y tarjetas de crédito) e hipotecarios.

Como consecuencia de ello se han creado en forma masiva nuevas líneas de crédito cada vez más orientadas a todos los agentes del mercado: a los bancos comerciales y de inversión se agregaron ahora los intermediarios hipotecarios, los fondos mutuos e incluso los fondos de inversión alternativa. Los créditos otorgados por la Reserva Federal al sector privado y la adquisición de cartera privada aumentaron casi 900.000 millones de dólares entre la semana terminada el 10 de septiembre y la finalizada el 12 de noviembre, cuando esta última alcanzó su nivel más elevado. A ello se agregaron las líneas de crédito concedidas a otros bancos centrales del mundo. En este período de dos meses y algunos días, la cartera total de la Reserva Federal aumentó en 1.300 millones de dólares (poco más del 9\% del PIB). Estos activos se financiaron con depósitos del gobierno en la Reserva Federal y mediante el excedente de reservas de los bancos depositadas en esta entidad — una de las manifestaciones de la acumulación de liquidez que está teniendo lugar a lo largo y ancho del mundo- - y que comenzaron a devengar intereses. Dado que las reservas bancarias forman parte de la base monetaria, esta última creció un $70 \%$ entre agosto y noviembre. Un proceso similar, aunque de menor magnitud, tuvo lugar en los demás bancos centrales de los países industrializados.

A estas medidas de los bancos centrales se sumaron los programas de rescate bancario encabezados por los distintos gobiernos. Al comienzo el panorama reveló la existencia de una descoordinación sin precedentes de las autoridades. En Estados Unidos, el partido de gobierno se opuso al rescate de 700.000 millones de dólares presentado por la administración Bush, que finalmente fue aprobado por el Congreso a comienzos de octubre gracias al apoyo de la oposición. En Europa, los gobiernos anunciaron una serie de iniciativas que competían entre sí, especialmente en materia de seguros sobre los depósitos. En general, las medidas introducidas por Gran Bretaña el 7 de octubre ordenaron los planes de rescate. Ante todo, se centraron en capitalizar las entidades financieras mediante fondos públicos, lo que en algunos casos ha implicado la nacionalización total de algunas de ellas (incluidos los gigantes hipotecarios Fannie Mae y Freddie Mac y el grupo AIG en los Estados Unidos). La segunda medida fue la ampliación del seguro sobre los depósitos y la garantía estatal de 
algunas líneas de crédito, sobre todo interbancarias, mientras que la tercera consistió en crear fondos para la adquisición de "activos tóxicos". Aunque este fue el centro de atención del paquete aprobado inicialmente en los Estados Unidos, posteriormente se abandonó como instrumento debido a las dificultades para hacer operativa la compra de activos complejos y heterogéneos. El rescate del Citibank anunciado a fines de noviembre de 2008 y el nuevo paquete británico de enero de 2009 representan una modalidad intermedia entre el segundo y el tercer tipo de medidas descritas, ya que los gobiernos asumieron una garantía pública sobre el exceso de pérdidas vinculadas a los activos tóxicos que continúan en poder de las instituciones (parte de ellos en el caso del Citibank). Curiosamente, hasta enero de 2009 los programas de rescate no habían incluido medidas de alivio para los deudores (en particular, los deudores hipotecarios pobres) y, pese a las presiones de algunos integrantes del Partido Demócrata estadounidense, tampoco se habían introducido modificaciones en la ley de quiebras que permitieran renegociar las hipotecas, al menos las de menor cuantía.

Las medidas aplicadas han servido para corregir algunas de las distorsiones más evidentes generadas por el colapso financiero de mediados de septiembre. La tasa de interés interbancaria, que se había elevado casi dos puntos porcentuales durante el mes posterior a la crisis, tendió a normalizarse desde mediados de octubre (véase el cuadro 2). La emisión de valores comerciales se reactivó después del mínimo alcanzado el 22 de octubre (véase el gráfico 1), mientras que las presiones sobre las líneas de crédito de la Reserva Federal se atenuaron desde mediados de noviembre (véase el cuadro 1). El ritmo de creación de base monetaria se redujo, pero no se interrumpió, generando una emisión acumulada de 855.000 millones de dólares entre agosto de 2008 y enero de 2009, equivalente a poco menos del $6 \%$ del PIB de los Estados Unidos. ${ }^{1}$

Por otra parte, contrariamente al objetivo de la política, la fuga hacia la calidad se manifestó al comienzo en una reducción de las tasas de interés de los bonos del Tesoro de muy corto plazo, que se convirtieron en un sustituto próximo al dinero, pero este proceso coincidió con un aumento de las tasas de mercado - $\mathrm{O}$, lo que es equivalente, con un incremento significativo de todos los márgenes de riesgo-. Desde noviembre,

\footnotetext{
${ }^{1}$ De acuerdo con la serie H.3 de la Reserva Federal, en las dos últimas semanas de enero de 2009 la base monetaria se elevó a 1.698 millones de dólares, poco más del doble de la de agosto de 2008 (843.000 millones de dólares).
}

sin embargo, todas las tasas de interés comenzaron a reducirse, aunque mucho más que las correspondientes a los títulos del Tesoro a largo plazo. En su conjunto, y pese a que desde mediados de agosto de 2007 las tasas de la Reserva Federal han disminuido de 5 a 6 puntos porcentuales, algunas continúan superando los niveles de ese entonces (bonos de las empresas de menor nivel de calificación y de los gobiernos estaduales y locales) y otras muestran reducciones modestas (bonos de las empresas altamente calificadas).

Esto significa que aunque la política estadounidense permitió superar la iliquidez total que caracterizó la tercera fase de la crisis, hasta enero de 2009 no había logrado reactivar el crédito, que entró más bien en un proceso de contracción generalizada en los últimos meses de 2008, cuando se amplió al crédito bancario. La inyección de capital público en los bancos ha sido un canal fundamental para darle algo de estabilidad al sistema, pero a comienzos de 2009 era evidente que este proceso no había culminado y que podría terminar en la nacionalización total de un conjunto más amplio de instituciones, especialmente en Gran Bretaña, pero también en los Estados Unidos y en algunos países de Europa continental. Por otra parte, no está claro que, en ausencia de una reactivación productiva, dicha capitalización sea suficiente para garantizar un mayor dinamismo del crédito.

Por su parte, la actividad económica ha venido experimentando una caída vertical, que en los países industrializados alcanzaría un ritmo anual equivalente del $5 \%$ al $6 \%$ en el último trimestre de 2008 y el primer trimestre de 2009. ${ }^{2}$ Entre los analistas hay consenso en que la eficacia de la política monetaria en los Estados Unidos es muy reducida y en que el país se encuentra de hecho en una "trampa de liquidez", que se expresa en particular en el atesoramiento de los títulos más líquidos -incluido el depósito del exceso de reservas de los bancos comerciales en la Reserva Federal-y en la marcada demanda de bonos del Tesoro a corto plazo. Por este motivo, la atención se ha desplazado hacia las medidas monetarias no convencionales antes mencionadas, orientadas directamente a reactivar y reducir el costo del crédito y a los paquetes fiscales. Estados Unidos ha anunciado el más grande de estos últimos, de unos 800.000 millones de dólares (poco menos del $6 \%$ del PIB). En otros países, los bancos centrales han

\footnotetext{
${ }^{2}$ Los anuncios del 30 de enero indican que el PIB de los Estados Unidos disminuyó a un ritmo del 3,8\% en el último trimestre, pero los analistas esperan que esa cifra sea revisada en un sentido aun más negativo.
} 
continuado la tarea, aún incompleta en Europa, de bajar las tasas de interés.

Una forma de resumir los sucesos recientes es señalar que la tercera fase de la crisis, caracterizada por la iliquidez total del sistema financiero, fue seguida desde noviembre por una cuarta en que ha desaparecido este problema, pero en que subsisten la severa descapitalización de las entidades financieras y la contracción del crédito y cuyo elemento dominante es el colapso de la actividad productiva en los países industrializados, que ha arrastrado a todo el mundo.

En 2009, la situación dependerá de la forma en que evolucionen los temas examinados. De acuerdo con la mayoría de las proyecciones de fines de 2008, en el segundo semestre del presente año las economías de los países industrializados, encabezadas por los Estados Unidos, tendrán un vuelco positivo. Es un escenario optimista. La experiencia del pasado en el mundo en desarrollo, al igual que la gran depresión en los Estados Unidos y la "década perdida" de Japón a fines del siglo XX, indican que en las crisis que como la actual implican menos apalancamiento y cambios radicales en los balances, el efecto recesivo tiende a ser fuerte y prolongado. La única proyección de 2008 que resultó acertada fue el escenario pesimista previsto por las Naciones Unidas, de acuerdo con el cual la recesión continuaría a lo largo del año 2009, generando una caída del 1,5\% del PIB de los países industrializados y del 0,4\% en el PIB mundial (Naciones Unidas, 2009, cuadro I.1). Dada la información reciente sobre la evolución de la actividad económica —incluida aquella sobre la marcada desaceleración de la economía china en el último trimestre de 2008-, incluso este escenario luce ahora optimista. El propio FMI (2009), que generalmente se cuenta entre los organismos optimistas en materia de proyecciones económicas, señaló a fines de enero que el PIB mundial a precios de mercado disminuiría un $0,6 \%$, casi dos puntos porcentuales menos que las estimaciones que había dado a conocer hace apenas dos meses antes. Por su parte, las proyecciones del sector privado son aún más pesimistas.

Conviene subrayar que a lo largo de la crisis uno de los principales problemas ha sido la falta de coordinación de las autoridades internacionales, con la notoria excepción de las medidas aplicadas por los bancos centrales a fin de mejorar la provisión de liquidez. Uno de los capítulos más recientes de esta descoordinación es la falta de consenso europeo sobre la necesidad de poner en marcha una política fiscal más expansiva. En todo caso, cabe recordar que Europa tiene estabilizadores automáticos más desarrollados que los Estados Unidos (en particular, seguros de desempleo más generosos) y que, por ello, sobre este país recae la responsabilidad de adoptar medidas fiscales discrecionales ambiciosas. Mucho se ha discutido, además, si los paquetes fiscales deben o no centrar su atención en la expansión del gasto, para garantizar un efecto cierto sobre la demanda agregada, o incluir medidas tributarias cuyos efectos en la demanda agregada son más inciertos.

Por otra parte, nunca había sido más evidente que es preciso mejorar la institucionalidad para coordinar las políticas macroeconómicas mundiales y manejar la globalización financiera. De hecho, la crisis también ha revelado la necesidad de crear una nueva institucionalidad europea e incluso estadounidense en materia de reglamentación, debido a la complejidad institucional del sistema de regulación y supervisión prudencial en los Estados Unidos, que involucra un sinnúmero de agencias tanto federales como estaduales.

\section{III}

\section{Los canales externos de transmisión de la crisis}

Como se señaló en la introducción a este ensayo, el auge que experimentó América Latina en el período 2003-2007 se basó en una combinación inusual de bonanza financiera, alza de precios de los productos básicos y alto nivel de remesas de los trabajadores migrantes. Por lo tanto, puede considerarse que la inversión de estas alteraciones positivas representa los tres canales externos de transmisión de la crisis hacia la región.

\section{Las remesas}

De los tres canales mencionados, la información más fragmentada de que se dispone es aquella sobre la evolución de las remesas de los trabajadores migrantes. En todo caso, sobre la base de las estadísticas de balanza de pagos de América Latina, está claro que el período de crecimiento acelerado de estas culminó en 2006. En los dos últimos años han aumentado a un ritmo más 
pausado (3\% medio), con una contracción moderada en 2008 en México. En este caso, la caída de la actividad constructora estadounidense fue el canal más importante de transmisión de la crisis a las remesas, dado que una proporción apreciable de los trabajadores del sector de la construcción de viviendas son migrantes mexicanos $(13,8 \%$, una cifra casi tres veces superior a la participación de mexicanos en la fuerza de trabajo de los Estados Unidos, que es del 5,1\%) (J.P. Morgan, 2008). Es posible que la baja de la construcción en España, un destino muy importante de los migrantes colombianos y ecuatorianos, haya tenido un efecto similar.

Sin embargo, es difícil prever un descenso marcado de las remesas en su conjunto. De acuerdo con los pronósticos del Banco Mundial, en 2009 ellas más bien se estancarían (Ratha, Mohopatra y Xu, 2008). Más aún, el poder de compra de las remesas tendería a aumentar en la medida en que se acompañen de una depreciación de las monedas en los países receptores. Por eso, curiosamente, su continuidad podría tener un efecto estabilizador en el consumo de los hogares.

\section{El comercio internacional}

Durante el período de bonanza reciente de 2003 a 2006 el volumen de comercio mundial aumentó un 9,3\% anual, duplicando con creces el incremento de la producción mundial a precios de mercado $(3,8 \%)$ (Naciones Unidas, 2009, cuadro I.1). Sin embargo, el ritmo de crecimiento de ambos indicadores ha sido muy sensible a los ciclos económicos y, por ende, más volátil que el del PIB mundial. Como resultado de ello, el comercio internacional se ha convertido en un mecanismo amplificador, tanto de los períodos de auge como de los de contracción de la actividad productiva. En 2007 y 2008 se redujo significativamente, creciendo apenas un $2 \%$ en septiembre de este último año (Naciones Unidas, 2009, gráfico I.9). De hecho, los datos parciales disponibles indican que en el último trimestre de 2008 hubo una contracción del comercio mundial. Según el Banco Mundial (2009, cuadro I.1), en 2009 disminuiría un 2,1\% y de acuerdo con el escenario pesimista de las Naciones Unidas (2009, cuadro I.1), un $3,1 \%$.

La contracción del volumen de comercio será el principal mecanismo de transmisión de la crisis hacia los países latinoamericanos y caribeños en su conjunto, pero afectará especialmente a aquellos en cuya estructura exportadora dominan las manufacturas y los servicios, es decir, México, Centroamérica y el Caribe. A su vez, las tendencias del precio de los productos básicos serán el factor determinante de la evolución de las exportaciones sudamericanas.

En los últimos años, la economía mundial experimentó la bonanza más espectacular de los precios de los productos básicos en más de un siglo, tanto en cuanto a duración (cinco años) como a intensidad y alcance (Banco Mundial, 2009, capítulo 2). Como lo indica el cuadro 3, sin embargo, el auge fue mucho más marcado en el caso de los productos de la minería, incluidos los energéticos, que en los agrícolas. Esto se manifiesta en

CUADRO 3

Precios reales de los productos básicos

(Deflactados según índice de precios de las manufacturas, 1945-1980 = 100)

\begin{tabular}{lcccrrr}
\hline & $\begin{array}{c}\text { Total no } \\
\text { petroleros }\end{array}$ & $\begin{array}{c}\text { Total } \\
\text { agropecuarios }\end{array}$ & $\begin{array}{c}\text { Agropecuarios } \\
\text { de clima tropical }\end{array}$ & $\begin{array}{c}\text { Otros } \\
\text { agropecuarios }\end{array}$ & Metales & Petróleo \\
\hline $1945-1970$ & 98,4 & 98,9 & 100,1 & 97,5 & 96,4 & 64,6 \\
$1971-1980$ & 104,1 & 103,0 & 99,6 & 106,4 & 109,4 & 192,1 \\
$1981-1990$ & 81,1 & 75,5 & 63,1 & 88,2 & 106,6 & 246,3 \\
$1991-1997$ & 75,3 & 73,7 & 57,9 & 89,9 & 82,4 & 139,5 \\
$1998-2003$ & 69,4 & 67,0 & 50,7 & 83,6 & 80,4 & 193,7 \\
2004 & 75,1 & 69,1 & 52,8 & 85,7 & 102,8 & 290,7 \\
2005 & 80,3 & 72,1 & 59,5 & 84,9 & 118,3 & 410,7 \\
2006 & 96,0 & 76,1 & 63,8 & 88,5 & 187,8 & 487,0 \\
2007 & 102,4 & 80,7 & 69,7 & 91,9 & 202,3 & 518,7 \\
2008 -I & 121,0 & 100,8 & 94,2 & 107,5 & 214,0 & 687,3 \\
2008 -II & 123,3 & 102,1 & 99,1 & 105,0 & 221,5 & 860,7 \\
2008 -III & 112,7 & 94,2 & 88,5 & 100,0 & 198,1 & 810,0 \\
2008 -oct. & 87,9 & 77,3 & 66,6 & 88,2 & 137,0 & 503,4 \\
2008-nov. & 80,3 & 72,6 & 58,3 & 87,0 & 116,3 & 374,2 \\
\hline
\end{tabular}

Fuente: José Antonio Ocampo y María Ángela Parra, "Los términos de intercambio de los productos básicos en el siglo XX", Revista de la CEPAL, No 79 (LC/G.2200-P), Santiago de Chile, abril de 2003, actualizado por el autor sobre la base de las mismas fuentes utilizadas. 
el hecho de que en su punto más alto, generalmente en el segundo trimestre de 2008, el precio real de los minerales superó con creces el de los años setenta (más el de los productos energéticos que el de los metales). En cambio, los productos agrícolas a duras penas alcanzaron los niveles de ese período.

Una consecuencia de lo anterior es que en el mundo en desarrollo en general la mejora de los términos de intercambio fue mucho más significativa para los exportadores de productos mineros, mientras que en el caso de los exportadores agrícolas ellos permanecieron más o menos constantes y en el de los exportadores de bienes manufacturados se deterioraron (Naciones Unidas, 2009, gráfico II.6). En América Latina, las mejoras más marcadas de la relación de intercambio se registraron en los países andinos, desde la República Bolivariana de Venezuela hasta Chile, todos ellos exportadores importantes de productos mineros, ${ }^{3}$ en tanto que Argentina, Brasil y Paraguay, exportadores de productos agrícolas, tuvieron apenas ligeras mejorías, incluso en 2008. Por su parte,

\footnotetext{
${ }^{3}$ Algunos no relacionan a Colombia con este patrón, pero en realidad dos quintas partes de la canasta exportadora de ese país son productos energéticos (petróleo y carbón) y metales (níquel y oro).
}

en todos los países centroamericanos y Uruguay, que son conocidos importadores de petróleo, dicha relación tuvo un deterioro, mientras que en México, que combina una exportación dominante de manufacturas con ventas externas de petróleo, ella fue levemente más favorable (véase el gráfico 2).

Esta diferencia entre los productos mineros y agrícolas indica que los factores determinantes de los precios de ambos grupos de bienes son muy diferentes. En el caso de los productos energéticos y mineros, el tema central ha sido la baja tasa de inversión resultante de los bajos precios que caracterizaron los mercados de este tipo de bienes entre mediados de los años ochenta y comienzos de la década actual. Dada la alta demanda generada por el crecimiento acelerado de los países en desarrollo durante el último lustro, incluida la elevada demanda china de metales, los precios tuvieron alzas marcadas. La inversión respondió en forma positiva, pero en todos los proyectos mineros existe un rezago significativo entre las decisiones de inversión y el aumento de la producción. En el caso de la agricultura, y pese a las señales de alarma a que dio lugar la crisis alimentaria del primer semestre de 2008, el desequilibrio entre la oferta y la demanda fue mucho más moderado. Una vía

GRÁFICO 2

América Latina y el Caribe (países seleccionados): ganancia o pérdida de términos de intercambio (En porcentajes del PIB)

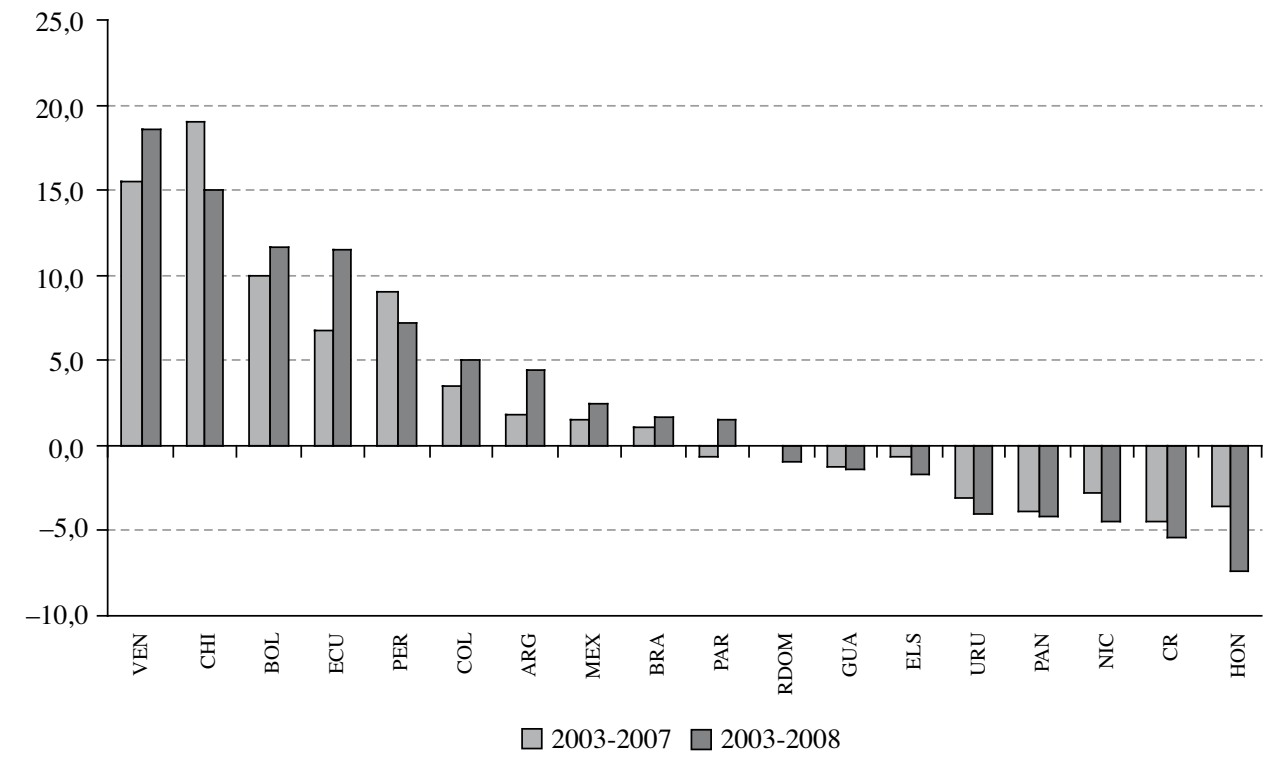

Fuente: elaboración propia sobre la base de datos de la Comisión Económica para América Latina y el Caribe (CEPAL). 
de transmisión importante fue, en este caso, que los altos precios de la energía se tradujeron en precios elevados de los productos agrícolas que se utilizan o sustituyen a los que se emplean para producir biocombustibles (Von Braun, 2007).

Durante el segundo semestre de 2007 y primero de 2008, período de fuerte aumento de precios de los productos básicos, la depreciación del dólar y la especulación financiera alimentaron las alzas. En todo caso, el quiebre de la tendencia de los precios tuvo lugar hacia mediados de 2008 y, por lo tanto, precedió al colapso financiero de septiembre del mismo año. Tras el derrumbe del sistema crediticio, los precios de los productos básicos, especialmente energéticos y mineros, entraron en caída libre. Aun así, en noviembre los precios de estos productos se mantenían por encima de los niveles reales de los años setenta. En cambio, los productos agrícolas de clima tropical habían vuelto a sus bajos niveles de los años noventa. En el caso de los de clima templado, la disminución fue más moderada.

Las perspectivas en materia de precios de los productos básicos son negativas. En noviembre se encontraban por debajo de las proyecciones más recientes del Banco Mundial (2009, cuadro I.4), que preveían una caída del $25 \%$ en el precio de los productos energéticos y del $23 \%$ en el de los distintos de los energéticos en 2009. A la caída acumulada hasta noviembre, habría que agregar, además, la experimentada por los productos básicos en diciembre.

La reducción del comercio internacional será quizá el canal más importante de transmisión de la crisis mundial a América Latina. No podría ser de otra manera, dado el mayor coeficiente de apertura que caracteriza a las economías latinoamericanas de hoy. El mayor beneficio en este campo será la inversión del deterioro de los términos de intercambio de los países importadores de petróleo. La experiencia histórica indica que durante las crisis también existen oportunidades vinculadas a los efectos positivos de un tipo de cambio más competitivo en la diversificación de la estructura productiva, pero para aprovecharlos habría que poner en marcha políticas de desarrollo productivo más activas, tal como lo ha propuesto la Comisión Económica para América Latina (CEPAL) (más recientemente en CEPAL, 2008a).

\section{Las corrientes de capital}

Una de las características sobresalientes de las corrientes financieras que fluyeron hacia el mundo en desarrollo durante las cuatro últimas décadas fue la modificación de los factores que alimentan los períodos de auge: mientras que en los años setenta fueron los créditos de consorcios bancarios destinados al sector público, en los noventa ese papel lo desempeñaron las emisiones de bonos internacionales y durante la coyuntura reciente los capitales de cartera.

La naturaleza de las corrientes financieras durante la bonanza reciente se aprecia mejor examinando las hojas de balance externo de las principales economías latinoamericanas (véase el cuadro 4$),{ }^{4}$ que muestra dos cambios notables. El primero es el aumento de los activos, sobre todo de las reservas internacionales, pero también de las inversiones directas y de cartera en el exterior, que en todos los casos han superado el crecimiento acelerado del PIB en dólares corrientes de los siete países analizados (que casi se duplicó entre 2003 y 2007). El segundo es el fuerte cambio en la composición de los pasivos, caracterizada esencialmente por la reducción del endeudamiento y la marcada presencia de pasivos de cartera accionarios. Estos últimos incluyen las inversiones realizadas en los países de la región por los fondos de inversión internacionales, que también participan en los mercados locales de bonos. Por lo tanto, la contrapartida de este proceso ha sido el auge de los mercados internos, tanto de bonos como accionarios, que de 2001 a 2007 se expandieron 15 puntos porcentuales del PIB. ${ }^{5}$ La valoración de los mercados accionarios se examinará más adelante.

Hay dos elementos adicionales de estas hojas de balance externo que vale la pena destacar. Por una parte, como resultado tanto del aumento de los activos como de la reducción de los pasivos, los pasivos financieros netos con el exterior disminuyeron notablemente: diez puntos del PIB entre 2003 y 2007. Esta es, además, una característica de las siete economías más grandes de la región. A fines de 2007, la posición financiera neta en tres de ellas (Argentina, Chile y República Bolivariana de Venezuela) era positiva y la de otras dos (Colombia y Perú) se acercaba al equilibrio. Por otra, la acumulación de reservas parece extremadamente sólida cuando se compara con los pasivos de deuda, pero mucho menos si el punto de referencia es la totalidad de los pasivos de cartera. Esto indica que puede considerarse que la acumulación de reservas es la contrapartida del aumento de esta clase de pasivos. De hecho, en los dos países

\footnotetext{
${ }^{4}$ Para un análisis más detallado de las corrientes de financiamiento externo hacia América Latina en los últimos años, véanse Jara y Tovar (2008) y Ocampo (2007).

${ }^{5}$ Ocampo y Tovar (2008) analizan más detalladamente el desarrollo de los mercados de bonos de los países latinoamericanos en la década actual.
} 
CUADRO 4

América Latina (siete países): hoja de balance externo

(En porcentajes del PIB a precios corrientes)

\begin{tabular}{|c|c|c|c|c|c|c|c|}
\hline & 2001 & 2002 & 2003 & 2004 & 2005 & 2006 & 2007 \\
\hline \multicolumn{8}{|l|}{ Activos } \\
\hline Totales $^{\mathrm{a}}$ & 26,5 & 29,7 & 31,9 & 31,5 & 31,4 & 32,4 & 37,5 \\
\hline Inversión directa en el exterior & 5,8 & 6,9 & 7,0 & 7,2 & 7,0 & 7,5 & 7,9 \\
\hline Activos de cartera & 2,1 & 2,4 & 3,2 & 3,2 & 3,5 & 3,9 & 4,8 \\
\hline Derivados & 0,0 & 0,0 & 0,0 & 0,1 & 0,0 & 0,0 & 0,0 \\
\hline Otras inversiones & 12,1 & 13,3 & 13,4 & 12,6 & 11,4 & 10,8 & 12,5 \\
\hline Reservas internacionales $^{\mathrm{a}}$ & 6,6 & 7,1 & 8,3 & 8,5 & 9,5 & 10,0 & 12,3 \\
\hline \multicolumn{8}{|l|}{ Pasivos } \\
\hline Totales ${ }^{\mathrm{a}}$ & 62,4 & 65,4 & 70,4 & 66,4 & 61,5 & 60,3 & 65,6 \\
\hline Inversión extranjera directa & 24,5 & 25,5 & 28,6 & 28,1 & 26,7 & 25,6 & 27,2 \\
\hline Pasivos de cartera & 19,8 & 20,1 & 23,1 & 22,9 & 22,8 & 23,8 & 28,0 \\
\hline Acciones & 5,5 & 4,9 & 7,2 & 8,4 & 10,4 & 13,0 & 16,9 \\
\hline Deuda & 14,3 & 15,2 & 15,9 & 14,5 & 12,3 & 10,9 & 11,1 \\
\hline Derivados & 0,0 & 0,0 & 0,0 & 0,1 & 0,1 & 0,2 & 0,3 \\
\hline Otras inversiones $^{\mathrm{a}}$ & 18,0 & 19,8 & 18,6 & 15,4 & 11,9 & 10,7 & 10,2 \\
\hline Activos - pasivos & $-35,8$ & $-35,7$ & $-38,4$ & $-34,9$ & $-30,1$ & $-27,9$ & $-28,1$ \\
\hline Inversión directa & $-18,8$ & $-18,6$ & $-21,6$ & $-20,9$ & $-19,7$ & $-18,0$ & $-19,2$ \\
\hline Financieros & $-17,1$ & $-17,1$ & $-16,8$ & $-14,0$ & $-10,4$ & $-9,9$ & $-8,9$ \\
\hline Reservas como porcentaje de la deuda & 20,3 & 20,4 & 24,0 & 28,3 & 39,1 & 46,5 & 57,9 \\
\hline Reservas como porcentaje de pasivos de cartera & 33,1 & 35,5 & 35,9 & 37,0 & 41,6 & 42,1 & 44,0 \\
\hline Mercado interno de capitales como porcentaje del PIB & 34,2 & 32,1 & 38,7 & 39,8 & 43,8 & 44,5 & 49,1 \\
\hline \multicolumn{8}{|l|}{ Activos - pasivos financieros } \\
\hline Argentina & $-0,3$ & 19,8 & 20,1 & 22,0 & 29,5 & 26,2 & 29,0 \\
\hline Brasil & $-34,9$ & $-36,4$ & $-35,2$ & $-31,0$ & $-24,1$ & $-23,8$ & $-28,9$ \\
\hline Chile & $-3,2$ & $-1,5$ & 3,9 & 13,5 & 17,3 & 27,6 & 42,7 \\
\hline Colombia & $-13,8$ & $-13,6$ & $-14,5$ & $-10,2$ & $-5,2$ & $-3,1$ & $-0,9$ \\
\hline México & $-17,6$ & $-16,7$ & $-18,6$ & $-18,4$ & $-19,3$ & $-21,1$ & $-16,7$ \\
\hline Perú & $-29,4$ & $-27,9$ & $-26,4$ & $-21,3$ & $-14,4$ & $-7,6$ & $-6,8$ \\
\hline Venezuela, Rep. Bol. de & 23,9 & 35,9 & 48,7 & 44,6 & 49,3 & 50,8 & 51,3 \\
\hline \multicolumn{8}{|l|}{ Reservas como porcentaje de pasivos de cartera } \\
\hline Argentina & 2,2 & $-14,2$ & 1,7 & 19,6 & 67,6 & 72,8 & 93,4 \\
\hline Brasil & 18,1 & 13,1 & 13,6 & 15,7 & 23,1 & 28,6 & 35,4 \\
\hline Chile & 142,4 & 145,8 & 108,3 & 98,9 & 93,3 & 98,3 & 83,6 \\
\hline Colombia & 78,8 & 88,1 & 84,2 & 91,8 & 102,7 & 96,8 & 114,6 \\
\hline México & 30,8 & 41,6 & 42,7 & 39,0 & 35,8 & 30,0 & 29,0 \\
\hline Perú & 131,1 & 125,4 & 105,2 & 114,4 & 91,7 & 98,2 & 97,5 \\
\hline Venezuela, Rep. Bol. de & 131,1 & 125,4 & 105,2 & 114,4 & 91,7 & 98,2 & 97,5 \\
\hline
\end{tabular}

Fuente: elaboración propia sobre la base de datos del Fondo Monetario Internacional (FMI), Estadísticas financieras internacionales [en línea]. Nota: PIB en dólares corrientes según la Comisión Económica para América Latina y el Caribe (CEPAL); mercado interno de capitales según el Banco de Pagos Internacionales. Los datos se refieren a las siete economías más grandes (Argentina, Brasil, Chile, Colombia, México, Perú y República Bolivariana de Venezuela).

a A estas cuentas se les restó el valor de los pasivos con el Fondo Monetario Internacional. 
más grandes de la región, a fines de 2007 las reservas solo cubrían una proporción relativamente baja de los pasivos de cartera y en cuatro (México, pero también - aunque con una posición mucho más sólida-Chile, Perú y República Bolivariana de Venezuela) ellas aumentaron en los últimos años a un ritmo inferior a dichos pasivos.

Esta mejora de las hojas de balance externo es, sin duda, el principal activo con que cuenta la región para enfrentar las condiciones internacionales menos favorables. Significa, en particular, que en el futuro pesará menos el espectro del alto endeudamiento externo público o, para ser más preciso, pesará en un menor número de países. Sin embargo, conviene subrayar que en los últimos años el componente más dinámico del financiamiento externo, las corrientes de cartera, nuevamente demostraron ser muy volátiles. Además, como se verá, el endeudamiento de algunas empresas privadas se ha transformado en un nuevo elemento de vulnerabilidad.

A lo largo del período de bonanza tendió a aumentar la importancia relativa del financiamiento externo como fuente de los excedentes de divisas de la región. Los saldos de la cuenta de capitales, que entre mediados de 2002 y mediados de 2004 habían sido prácticamente nulos, se recuperaron a partir de entonces y comenza- ron a superar a aquellos de la cuenta corriente como fuente de los superávits de la balanza de pagos. Desde mediados de 2006 hasta mediados de 2007, la entrada de capitales se convirtió en una verdadera avalancha. En efecto, en seis de los siete países más grandes de la región (exceptuada la República Bolivariana de Venezuela), el excedente de la balanza de pagos en el último trimestre de 2006 y el primer semestre de 2007 se aproximó a los 113.000 millones de dólares, cerca de 100.000 millones de los cuales correspondieron a la cuenta de capitales (aproximadamente dos tercios se dirigieron a Brasil y el resto a las otras cinco economías) (Ocampo, 2007).

El gráfico 3, en que se reproduce la trayectoria de las emisiones mensuales de bonos latinoamericanos en los mercados internacionales, confirma que el financiamiento alcanzó su mayor nivel entre mediados de 2006 y mediados de 2007, período en que las emisiones fueron crecientes pero inestables y en que aumentó el predominio de las empresas privadas (cerca del 70\%). En general, las emisiones de las empresas tienen un mayor costo y un plazo promedio inferior al de los bonos gubernamentales y por ello exigen una mayor rotación del endeudamiento. Por estos motivos, son más vulnerables a las variaciones de la disponibilidad de capital.

GRÁFICO 3

Emisiones de bonos en los mercados internacionales

(En millones de dólares)

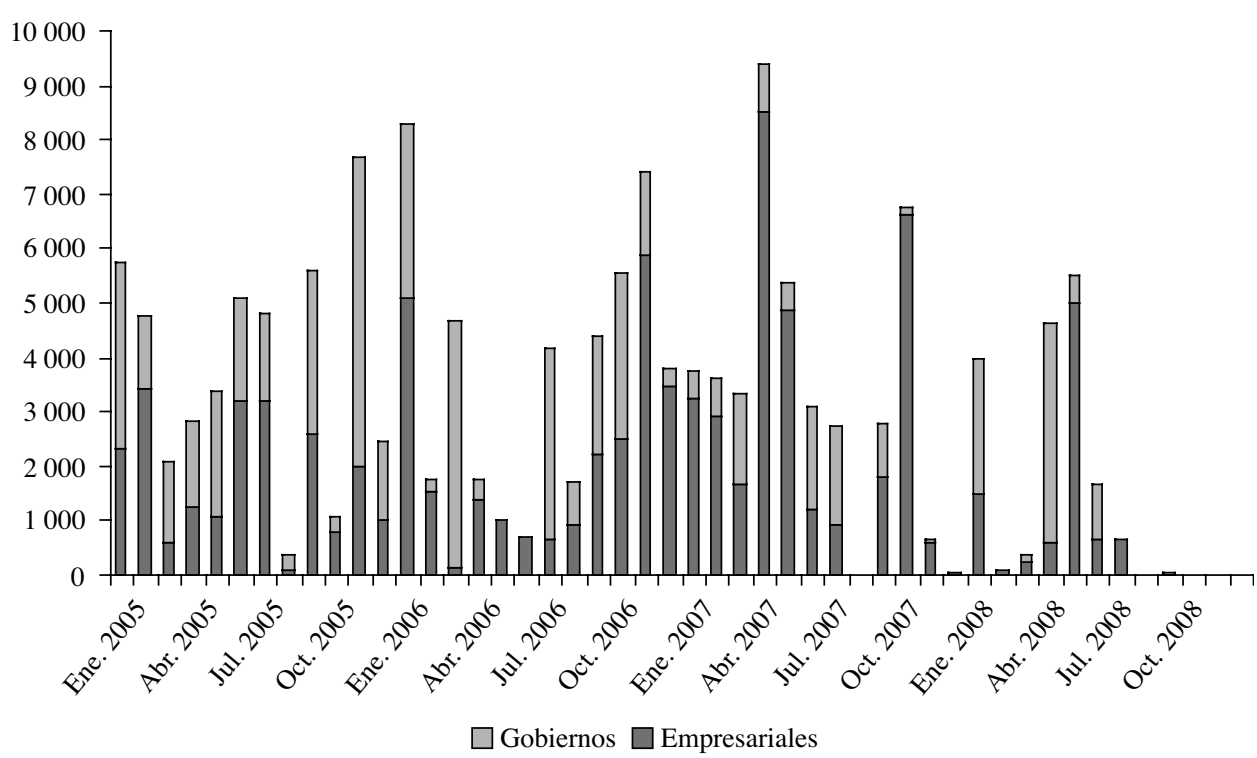

Fuente: Comisión Económica para América Latina y el Caribe (CEPAL) sobre la base de datos de J. P. Morgan. 
El gráfico 4 muestra otro elemento destacado del período de bonanza: la fuerte reducción del costo del financiamiento externo. Desde mediados de 2004, los márgenes de riesgo (spreads) de los títulos latinoamericanos, así como aquellos del conjunto de mercados emergentes, se situaron en niveles sistemáticamente inferiores a los que prevalecieron antes de la crisis asiática. Además, estos márgenes que al comienzo eran más altos que la media de los mercados emergentes tendieron a aproximarse a dicho promedio. Por otra parte, pese a que este período también se caracterizó por un aumento de las tasas de interés de la Reserva Federal (a partir de septiembre de 2004), las tasas de los títulos del Tesoro a largo plazo, que sirven como punto de referencia para la fijación de los precios en los mercados internacionales de bonos, no se vieron mayormente afectadas. Por este motivo, la baja de los márgenes de riesgo se tradujo en una marcada caída de los costos del financiamiento externo: de un $10 \%$ en el primer semestre de 2004 a poco menos del $7 \%$ en su punto más bajo, en abril a mayo de 2007. Esta tendencia se vio alterada en dos ocasiones: en marzo de 2005, por el alza generalizada de las tasas de interés en todos los mercados, y en el segundo trimestre de 2006, como reflejo de una perturbación más específica de los mercados emergentes cuyo epicentro fue Shanghai. Cabe agregar, además, que la reducción del costo del financiamiento fue generalizada en la región, aunque moderada en los dos países que ya eran considerados de bajo riesgo antes del período de bonanza (Chile y México).

Esta "exuberancia" de los mercados financieros se transmitió a las economías latinoamericanas por tres vías diferentes. La primera fue la presión a la baja de las tasas de interés internas generada por la reducción de los costos del financiamiento externo. En segundo lugar, y en forma a veces complementaria, la presión se reflejó en el tipo de cambio. Finalmente, el gran apetito de riesgo se manifestó en una inflación en los mercados accionarios. El gran auge de las bolsas de valores latinoamericanas se inició a mediados de 2004, es decir, cuando comenzaron a bajar rápidamente los márgenes de riesgo-país de los países de la región. En promedio, las cotizaciones de las bolsas de valores de las siete economías más grandes de la región, medidas en dólares, se cuadruplicaron entre mediados de 2004 y mediados de 2007 (véase el gráfico 5).

La crisis financiera internacional se difundió de manera compleja a lo largo del tiempo y tuvo efectos diferentes en los distintos países de la región. El impacto inicial, durante el tercer trimestre de 2007, fueron una

GRÁFICO 4

América Latina y países emergentes: rendimiento de los bonos soberanos

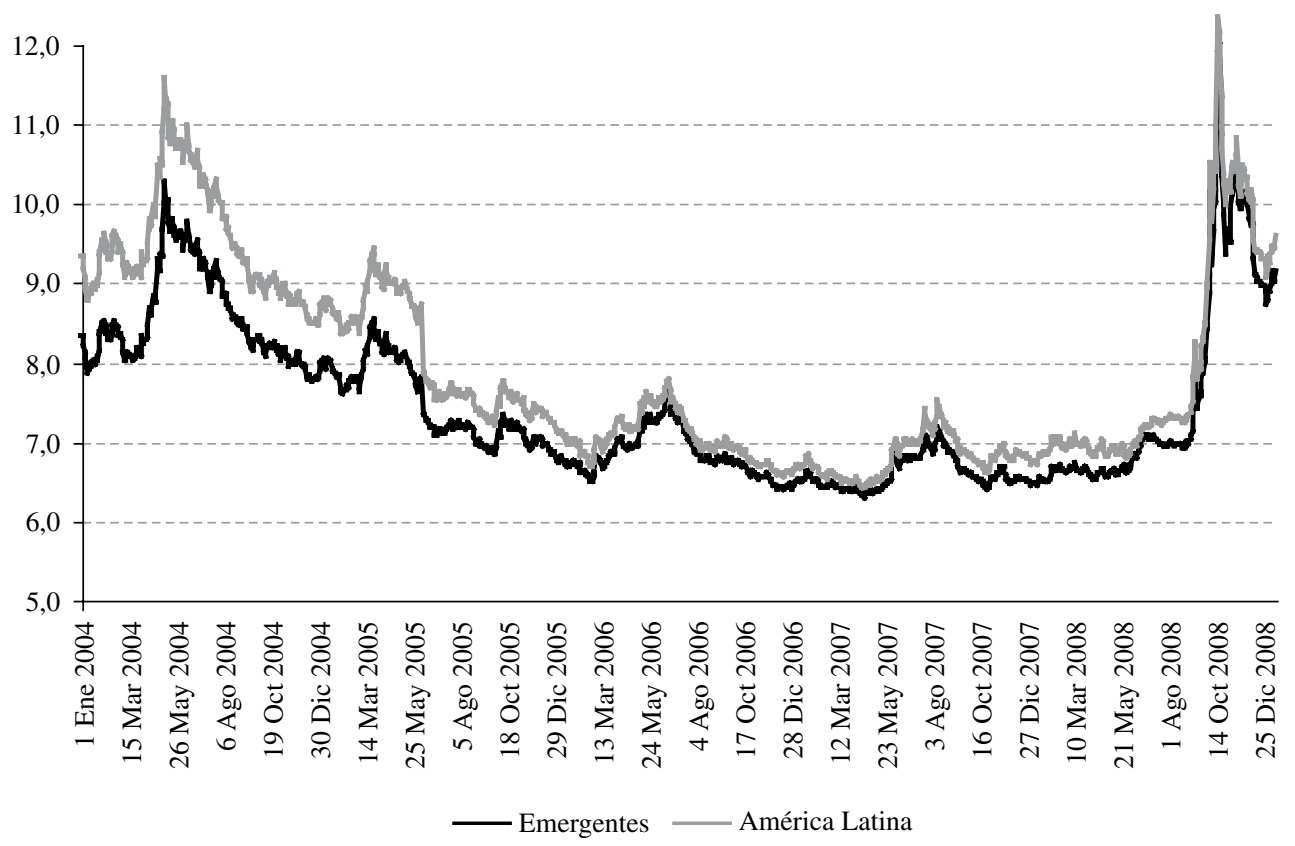

Fuente: elaboración propia sobre la base de datos de J.P. Morgan. 
GRÁFICO 5

Cotizaciones de la bolsa de valores

(Julio 2003-junio 2004 = 100)

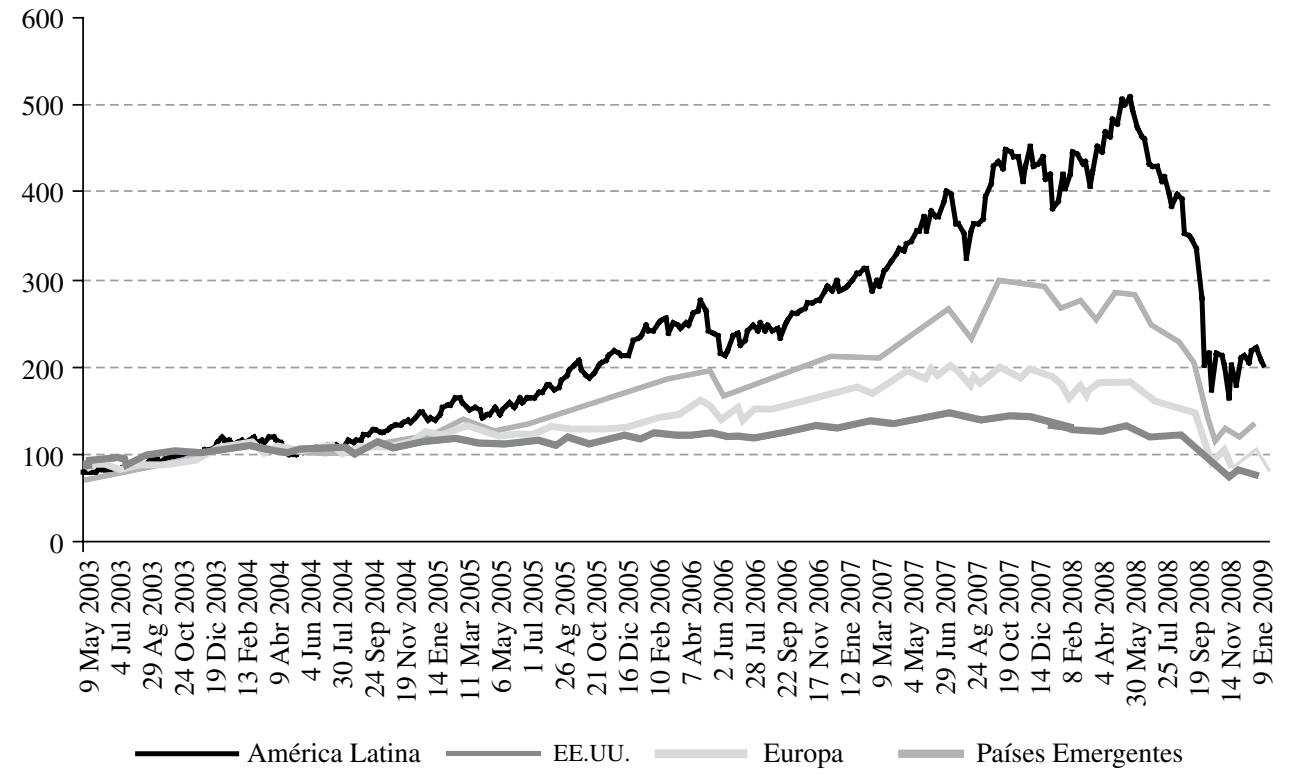

Fuente: elaboración propia sobre la base de datos de Morgan Stanley.

fuerte caída de las corrientes de capital y de las emisiones de bonos (véase el gráfico 3), un aumento moderado de los costos del financiamiento (véase el gráfico 4) y una baja también moderada de las bolsas, que se invirtió rápidamente (véase el gráfico 5). Por otra parte, si se compara con la perturbación anterior del mercado, de mayo a julio de 2006, los márgenes fueron más volátiles entre julio y septiembre de 2007, pero sus efectos fueron diversos. Exhibiendo un patrón que luego se acentuaría y que refleja un elemento del llamado "riesgo político", el aumento y la volatilidad de los spreads fueron mayores en Argentina y República Bolivariana de Venezuela. Por su parte, al igual que de mayo a julio de 2006, en Brasil y Colombia el tipo de cambio fue más sensible a los movimientos de corto plazo de los márgenes; México también mostró una fuerte correlación entre ambas variables, pero con niveles mucho más bajos de volatilidad. Chile y Perú fueron las economías menos afectadas (véase el cuadro 5).

Esta turbulencia fue sucedida, sin embargo, por el "veranillo" que se caracterizó por una nueva reducción de los costos del financiamiento y una renovación de las corrientes de financiación. Estas últimas, empero, se mantuvieron por debajo de los niveles anteriores y se tornaron más irregulares, como se percibe en las emisiones mensuales de bonos. A diferencia de los patrones mundiales - breve recuperación en octubre de 2007, seguida de una tendencia descendente-, las cotizaciones de las bolsas latinoamericanas, medidas en dólares, recuperaron su tendencia ascendente y, de hecho, alcanzaron su mayor valoración en mayo de 2008, aunque en gran medida como reflejo de la fuerte apreciación del real brasileño.

La nueva alteración del mercado se produjo en junio de 2008 y, en ese sentido, precedió claramente al colapso financiero de septiembre. De hecho, coincidió con el quiebre de los precios de los productos básicos. Esta relación se explica por el hecho de que muchas de las multinacionales emergentes de América Latina son productoras de productos básicos o commodities industriales como acero y cemento. Las emisiones de bonos se desplomaron en junio y julio y desaparecieron del mercado a partir de agosto. Los costos del financiamiento se elevaron medio punto porcentual ya antes del colapso de septiembre de 2008. La volatilidad de los márgenes no fue muy diferente de aquella de la perturbación que tuvo lugar en el tercer trimestre de 2007. Se acentuó la separación de Argentina y República Bolivariana de Venezuela de los demás países más grandes y nuevamente en Brasil y Colombia el tipo de cambio se mostró más 
CUADRO 5

América Latina (países seleccionados): volatilidad de los márgenes y tipos de cambio en períodos de turbulencia

\begin{tabular}{|c|c|c|c|c|c|c|c|c|}
\hline & Argentina & Brasil & Chile & Colombia & México & Perú & Ven., R.B. de & EMBI + \\
\hline \multicolumn{9}{|l|}{ Volatilidad de los márgenes ${ }^{\mathrm{a}}$} \\
\hline May 2006-Jul 2006 & 26,2 & 19,6 & 3,6 & 27,7 & 14,7 & 10,1 & 20,9 & 16,4 \\
\hline Jul 2007-Sep 2007 & 60,6 & 21,9 & 14,5 & 31,6 & 15,0 & 23,5 & 64,6 & 25,0 \\
\hline Jun 2008-Sep 12/2008 & 58,5 & 24,2 & 7,0 & 24,3 & 22,1 & 24,0 & 48,0 & 24,5 \\
\hline Sep 15/2008 - Ene 2009 & 352,4 & 79,4 & 61,4 & 104,7 & 82,4 & 92,6 & 306,6 & 126,5 \\
\hline \multicolumn{9}{|l|}{ Márgenes medios } \\
\hline May 2006-Jul 2006 & 362,8 & 249,3 & 81,0 & 215,4 & 134,3 & 167,5 & 207,6 & \\
\hline Jul 2007-Sep 2007 & 414,2 & 187,3 & 105,6 & 167,3 & 111,9 & 151,3 & 389,2 & \\
\hline Jun 2008-Sep 12/2008 & 632,5 & 226,5 & 173,0 & 211,5 & 168,5 & 190,1 & 623,4 & \\
\hline Sep 15/2008 - Ene 2009 & 1572,6 & 450,7 & 323,5 & 502,6 & 384,0 & 470,1 & 1492,2 & \\
\hline \multicolumn{9}{|l|}{ Volatilidad del tipo de cambio ${ }^{\text {b }}$} \\
\hline May 2006-Jul 2006 & 0,56 & 3,24 & 2,11 & 3,12 & 1,81 & 0,57 & 2,24 & \\
\hline Jul 2007-Sep 2007 & 0,78 & 2,95 & 0,91 & 4,51 & 1,21 & 0,57 & 0,00 & \\
\hline Jun 2008-Sep 12/2008 & 0,59 & 3,16 & 2,74 & 5,99 & 1,55 & 2,17 & 0,00 & \\
\hline Sep 15/2008 - Ene 2009 & 3,63 & 8,20 & 6,28 & 3,64 & 7,70 & 1,86 & 0,00 & \\
\hline \multicolumn{9}{|l|}{ Tipo de cambio medio } \\
\hline May 2006-Jul 2006 & 3,07 & 2,20 & 535 & 2494 & 11,16 & 3,26 & 2,59 & \\
\hline Jul 2007-Sep 2007 & 3,14 & 1,92 & 520 & 2041 & 10,96 & 3,15 & 2,15 & \\
\hline Jun 2008-Sep 12/2008 & 3,03 & 1,62 & 507 & 1818 & 10,26 & 2,89 & 2,15 & \\
\hline Sep 15/2008 - Ene 2009 & 3,32 & 2,23 & 628 & 2260 & 12,87 & 3,09 & 2,15 & \\
\hline \multicolumn{9}{|c|}{ Relación entre tipo de cambio y EMBI +} \\
\hline May 2006-Jul 2006 & 0,789 & 0,832 & 0,796 & 0,885 & 0,755 & $-0,388$ & 0,477 & \\
\hline Jul 2007-Sep 2007 & 0,818 & 0,658 & 0,364 & 0,789 & 0,930 & 0,059 & 0,000 & \\
\hline Jun 2008-Sep 12/2008 & $-0,145$ & 0,440 & 0,752 & 0,788 & 0,177 & 0,375 & 0,000 & \\
\hline Sep $15 / 2008$ - Ene 2009 & 0,751 & 0,876 & 0,901 & 0,678 & 0,901 & 0,808 & 0,000 & \\
\hline
\end{tabular}

Fuente: elaboración propia sobre la base de datos de J. P. Morgan Chase.

Nota: $\mathrm{EMBI}=$ Índice de títulos de los mercados emergentes (Emerging Markets Bond Index).

a Desviación estándar

b Coeficiente de variación

inestable. Las bolsas tuvieron una fuerte caída, pero antes del trastorno de septiembre se encontraban todavía en un nivel promedio tres veces y media superior al de mediados de 2004.

El colapso de mediados de septiembre de 2008 acentuó drásticamente estas tendencias. ${ }^{6}$ Se paralizaron los créditos de todo tipo y se produjo una salida de capitales a través de canales un tanto inesperados: la venta de títulos a lo largo y ancho del mundo para poder satisfacer el retiro de depósitos de los fondos mutuos y de inversión alternativa en Estados Unidos y el desmantelamiento de las operaciones de acarreo (carry trade) que se habían venido realizando desde Japón, uno de cuyos beneficiarios

\footnotetext{
${ }^{6}$ El ensayo reciente de Bustillo y Velloso (2009) ofrece un análisis detallado de los efectos de la crisis financiera internacional en las economías latinoamericanas.
}

había sido Brasil. Esto generó una fuerte depreciación de todas las monedas latinoamericanas, conjuntamente con una apreciación del dólar y el yen en los mercados internacionales. Además, las oscilaciones de los tipos de cambio provocaron pérdidas cuantiosas en los mercados de futuro, especialmente de Brasil y México. El monto de las salidas netas de capital que tuvieron lugar en América Latina durante el último trimestre de 2008 se desconoce, pero la pérdida de reservas en la mayoría de los países es una manifestación del fenómeno. Los demás efectos sí se conocen con precisión: los costos del financiamiento se elevaron apreciablemente (véase el gráfico 4) y las bolsas de valores tuvieron caídas muy superiores a las de los países industrializados (véase el gráfico 5); los márgenes se tornaron muy volátiles y en todos los países aumentó su correlación con la evolución del tipo de cambio (véase el cuadro 5); Brasil, Chile y México fueron ahora los países de mayor inestabilidad 
cambiaria, mientras que Colombia se mostró más estable que en los episodios anteriores, quizás porque la exigencia de encaje a las entradas de capital había reducido los capitales más volátiles; y la diferencia entre los márgenes de Argentina y República Bolivariana de Venezuela y los de las demás economías más grandes de América Latina se amplió significativamente, hasta alcanzar los 10 o más puntos porcentuales.

Acorde con la evolución de las tasas de interés en los Estados Unidos (véase el cuadro 2), se comprueba que los costos del financiamiento alcanzaron su nivel más alto a fines de octubre (12,35\% el 23 de octubre), para luego reducirse y tender a estabilizarse entre un $9 \%$ y un $10 \%$ a partir de mediados de diciembre, niveles no muy diferentes a los anteriores al auge que se inició en 2004 y dos a tres puntos porcentuales superiores a los que habían sido característicos antes de la crisis financiera de los Estados Unidos. La mayor presión sobre los mercados cambiarios también se produjo entre mediados de septiembre y fines de octubre; aunque desde entonces las monedas se han depreciado menos, los mercados siguieron siendo muy volátiles. Las bolsas tendieron igualmente a estabilizarse $\mathrm{y}$, de hecho, en América Latina lo hicieron en niveles superiores a los de mediados de 2004, a diferencia de lo que aconteció en los demás mercados (véase el gráfico 5).

Aunque los peores síntomas del colapso financiero vinculados a la iliquidez total que caracterizó la tercera fase de la crisis financiera de los Estados Unidos parecen haberse superado, subsisten sus efectos más permanentes.
Todas las proyecciones existentes indican que en el futuro inmediato las corrientes de capital privado se mantendrán en bajos niveles. Las proyecciones del Instituto de Finanzas Internacionales (2009), por ejemplo, indican que en 2009 las corrientes privadas de crédito hacia el conjunto de las economías emergentes serán negativas, en comparación con los flujos netos superiores a los 600.000 millones de dólares en 2007, pero que se detendrá la fuerte salida de capitales de cartera que tuvo lugar en 2008. Todos los estudios indican que el problema más crítico se relacionará con la rotación del endeudamiento de las grandes empresas de la región (véase, por ejemplo, J.P. Morgan, 2009). Por lo tanto, la fuerte dependencia de dichas empresas de los productos básicos o commodities industriales, así como los plazos de financiamiento mucho más breves, serán la principal debilidad de la cuenta de capitales.

Estos problemas, así como las grandes incertidumbres vinculadas a la solución todavía incompleta de la crisis financiera en el mundo industrializado, permiten prever que la debilidad del financiamiento externo privado se prolongará por algún tiempo. Sin embargo, es posible que en América Latina la crisis de la cuenta de capitales sea menos aguda que en oportunidades anteriores, como consecuencia de las mejores condiciones iniciales en materia de endeudamiento externo y nivel de reservas. Además, un efecto secundario favorable del nuevo contexto ha sido el freno de las fuertes presiones a la revaluación experimentadas por varios países de la región durante el auge. Estos temas serán el centro de atención del acápite siguiente.

\section{IV}

\section{La vulnerabilidad de los países latinoamericanos}

La historia de América Latina desde los años setenta está marcada no solo por grandes perturbaciones externas, tanto positivas como negativas, sino también por políticas macroeconómicas que tienden a reforzar en vez de atenuar los efectos de dichas conmociones en la actividad económica interna, esto es, políticas macroeconómicas procíclicas. El problema fundamental de este comportamiento es que durante las fases favorables del ciclo económico surgen una serie de vulnerabilidades, básicamente déficits públicos o privados que generan altos niveles de endeudamiento y cuya contrapartida son los déficits en la cuenta corriente de la balanza de pagos, alimentados también por una sobrevaluación de las monedas nacionales. Dichas vulnerabilidades quedan de manifiesto cuando se terminan las condiciones externas excepcionales y hay que realizar severos ajustes macroeconómicos, sea de carácter fiscal (en que se combinan diversos grados de recorte del gasto y aumento de los impuestos), políticas monetarias y crediticias restrictivas y fuertes ajustes del tipo de cambio.

Frente a este patrón del pasado, se ha señalado que la bonanza económica reciente provocó un cambio 
importante de la política macroeconómica, lo que se refleja en la mayor prioridad atribuida a los equilibrios macroeconómicos (véase, entre otros, CEPAL, 2008c). Según los defensores de esta visión, prueba de ello son las cuentas públicas más sanas y los superávits de la cuenta corriente que caracterizaron a la región durante el período de auge.

Esta interpretación de la historia económica reciente de América Latina debe matizarse, sin embargo, en varios sentidos. Una lectura mucho más adecuada es la que presenta el Banco Interamericano de Desarrollo (2008), basada en gran medida en el trabajo de Izquierdo, Romero y Talvi (2008) y que coincide con la que sostuve en un ensayo anterior (Ocampo, 2007). De acuerdo con esta visión alternativa, la causa del buen desempeño reciente fue la intensidad de los factores externos que facilitaron el auge, puesto que, en general, la política económica siguió siendo procíclica. Los elementos más importantes y comunes de ruptura con el pasado fueron el menor endeudamiento externo del sector público y la acumulación de reservas internacionales.

En el cuadro 6 se presenta un resumen de la evolución de los indicadores fiscales. Como puede apreciarse, en 2008 solo tres países tuvieron un déficit del gobierno central superior al 2\%: Brasil, Colombia y República
Dominicana. Además, en casi todos los países la deuda del gobierno central expresada como proporción del PIB fue significativamente inferior a la que existía al inicio de la crisis, salvo una vez más Brasil y Colombia, al igual que Argentina y Uruguay. Sin embargo, estos resultados fiscales positivos obedecieron ante todo a los ingresos públicos excepcionales y no a las políticas fiscales, que por lo general continuaron siendo procíclicas, con algunas excepciones. ${ }^{7}$ La más notable es Chile, país en que desde hace casi una década se han seguido reglas de balance estructural en materia fiscal, reforzadas durante el período de auge económico mediante dos fondos de estabilización orientados a ahorrar los excedentes fiscales generados por los altos precios del cobre: un Fondo de estabilización económica y social y un Fondo de reserva de pensiones.

Como lo muestra el cuadro 6, la elasticidad del gasto primario en relación al PIB fue superior a la unidad en casi todas las economías de la región. Sin embargo, de acuerdo con las reglas anticíclicas el gasto debería aumentar significativamente menos que el PIB durante

\footnotetext{
${ }^{7}$ Véase, en particular, BID (2008, capítulo 3). Un estudio de la CEPAL (2008b, capítulo IV) contiene también algunas consideraciones importantes sobre el tema.
} CUADRO 6

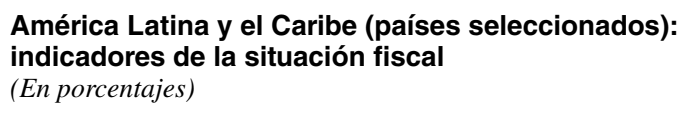

\begin{tabular}{|c|c|c|c|c|c|c|}
\hline & \multicolumn{2}{|c|}{$\begin{array}{c}\text { Superávit o déficit del } \\
\text { gobierno central } \\
\text { (en porcentajes del PIB) }\end{array}$} & \multicolumn{3}{|c|}{$\begin{array}{l}\text { Deuda del gobierno central } \\
\text { (en porcentajes del PIB) }\end{array}$} & \multirow{2}{*}{$\begin{array}{l}\text { Crecimiento real } \\
\text { del gasto primario } \\
\text { 2003-2007 }\end{array}$} \\
\hline & 2007 & 2008 & 2007 & 2008 & $\begin{array}{c}\text { Cambio } \\
1998-2008\end{array}$ & \\
\hline Argentina & 0,6 & 1,0 & 55,7 & 48,0 & 10,4 & 11,9 \\
\hline Bolivia & 2,3 & 3,0 & 37,1 & 30,7 & $-24,4$ & 5,0 \\
\hline Brasil & $-2,0$ & $-2,6$ & 32,7 & 30,1 & 5,9 & 9,0 \\
\hline Chile & 8,8 & 6,9 & 4,1 & 3,5 & $-8,6$ & 2,5 \\
\hline Colombia & $-3,0$ & $-2,7$ & 35,2 & 33,2 & 11,1 & 7,9 \\
\hline Costa Rica & 0,6 & $-0,5$ & 27,7 & 23,5 & $-19,4$ & 5,1 \\
\hline Ecuador & $-0,1$ & $-0,1$ & 27,5 & 22,6 & $-34,4$ & 10,3 \\
\hline El Salvador & $-0,2$ & $-0,6$ & 34,5 & 31,2 & $-2,1$ & 0,4 \\
\hline Guatemala & $-1,5$ & $-1,2$ & 21,7 & 19,3 & 2,9 & 2,9 \\
\hline Honduras & $-2,9$ & $-1,9$ & 17,4 & 17,4 & $-57,6$ & 7,4 \\
\hline México & 0,0 & 0,0 & 21,1 & 20,4 & $-7,4$ & 5,9 \\
\hline Nicaragua & 0,6 & 0,8 & 42,2 & 34,6 & $-89,6$ & 6,4 \\
\hline Panamá & 1,2 & $-1,0$ & 53,2 & 46,6 & $-15,4$ & 8,2 \\
\hline Paraguay & 1,0 & 0,5 & 17,3 & 12,1 & $-8,4$ & 4,4 \\
\hline Perú & 1,8 & 2,3 & 27,2 & 22,8 & $-14,4$ & 7,4 \\
\hline República Dominicana & 0,6 & $-3,2$ & 19,0 & 16,7 & $-1,5$ & 10,2 \\
\hline Uruguay & $-1,7$ & $-1,0$ & 50,7 & 39,9 & 15,9 & 6,4 \\
\hline Venezuela, Rep. Bol. de & 3,0 & $-1,8$ & 19,3 & 14,0 & $-15,4$ & 13,4 \\
\hline
\end{tabular}

Fuente: elaboración propia sobre la base de datos de la Comisión Económica para América Latina y el Caribe (CEPAL). 
los períodos de auge económico, es decir, la elasticidad del gasto en función del PIB debe ser menor que uno. Las excepciones, además de Chile, fueron El Salvador y Guatemala. Si bien hay otros países en que la elasticidad fue inferior a la unidad, el incremento del gasto primario real durante la bonanza superó el ritmo de crecimiento a largo plazo de dichas economías.

Este comportamiento procíclico de la política fiscal contrasta con el complejo aparato institucional introducido desde fines de los años noventa, que se manifestó en el diseño de numerosas leyes de responsabilidad fiscal y en la creación de fondos de estabilización. La preasignación de los recursos y el cambio de las reglas de juego pertinentes indican que hasta el momento los efectos de estas instituciones fiscales han sido limitados (Jiménez y Tromben, 2006).

La evolución de las cuentas externas también revela un patrón que dista de un enfoque de política orientado a generar superávits en la cuenta corriente de la balanza de pagos. Nuevamente, el factor externo determinante fue la marcada mejora de los términos de intercambio. El gráfico 6 muestra una estimación del balance en cuenta corriente de la región en su conjunto, sin y con ajustes por términos de intercambio. En este último caso, se toma como base el año anterior al auge económico, esto es, 2003. Como puede apreciarse, el superávit de la cuenta corriente obedeció exclusivamente a la mejora de la relación de intercambio. Ajustada en función de esta variable, la cuenta corriente registró un déficit creciente durante todo el período de bonanza, que en 2008 alcanzó un nivel equivalente al 5\% del PIB, cifra muy superior a la observada en las economías latinoamericanas antes de la crisis de fines del siglo XX.

El cuadro 7 muestra un panorama más detallado. Como puede apreciarse, las únicas economías que registraron un superávit en la cuenta corriente hasta 2008 fueron tres exportadoras de hidrocarburos -Bolivia, Ecuador y República Bolivariana de Venezuela- y Argentina. Otras dos, de base exportadora minera (Chile y Perú), tuvieron un superávit hasta 2007, pero este se redujo notablemente en 2008. Como lo indica el cuadro 7, ajustado por la evolución de los términos de intercambio, el déficit en cuenta corriente de ambos países ya era apreciable en 2007. Brasil siguió una trayectoria similar, aunque a partir de un superávit más modesto. Las únicas economías que registraron un ligero superávit en la cuenta corriente en 2008, ajustado según los términos de intercambio, fueron Bolivia y Uruguay. En este último, el déficit corriente obedeció, por lo tanto, a los altos precios de los hidrocarburos importados. Por lo demás, esto indica que dado el colapso de los precios de los productos mineros y energéticos, los países que poseen este tipo de base exportadora deberán enfrentar un importante proceso de ajuste en los próximos años.

Una de las explicaciones básicas del deterioro de la cuenta corriente a lo largo del período de auge económico

GRÁFICO 6

América Latina: cuenta corriente con y sin ajustes según términos de intercambio

(En porcentajes, base 2003)

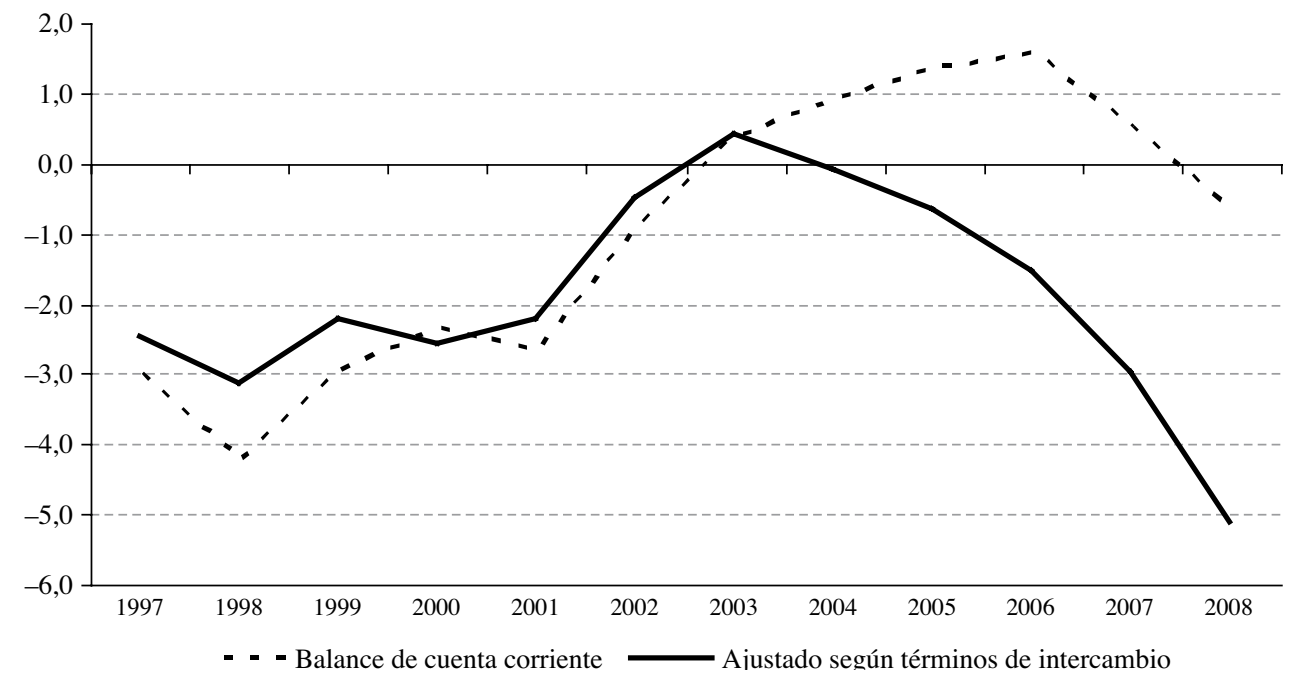

Fuente: elaboración propia sobre la base de datos de la Comisión Económica para América Latina y el Caribe (CEPAL). 


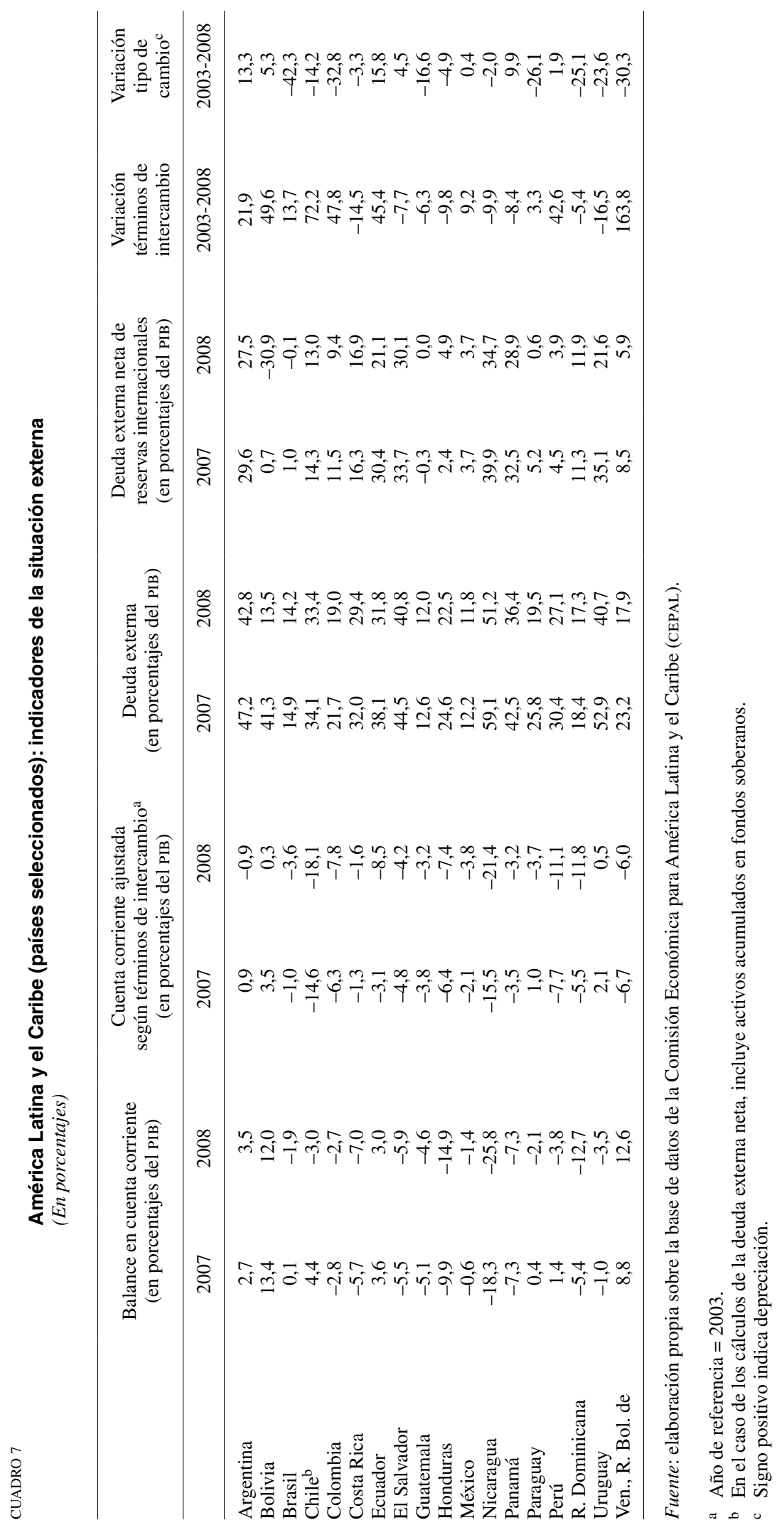


fue, como en el pasado, la tendencia a la apreciación real de las monedas. Como lo señala el cuadro 7, esta fue particularmente intensa en Brasil, Colombia y República Bolivariana de Venezuela, pero también en varias economías más pequeñas (Guatemala, República Dominicana y Uruguay). Chile también experimentó una apreciación real del peso, aunque más moderada. Las excepciones más notables al respecto fueron Bolivia y Perú; Argentina también lo fue hasta el año 2006, pero la devaluación real que se aprecia en el cuadro 7 obedece más bien a la subestimación oficial del ritmo inflacionario en los últimos años. La devaluación real que experimentó la moneda estadounidense durante la bonanza favoreció a las tres economías dolarizadas (Ecuador, El Salvador y Panamá).

Por otra parte, el gráfico 7 revela que los únicos aspectos en que las economías latinoamericanas muestran una mejora sistemática y consistente en relación con el pasado son el endeudamiento público externo y la acumulación de reservas internacionales. Para corregir los efectos de las variaciones del tipo de cambio real en el PIB, las estimaciones se realizaron a tipos de cambio de paridad de 2000. Como puede apreciarse, hubo una mejora significativa en materia de endeudamiento externo neto, gracias al menor nivel de endeudamiento registrado hasta 2006 y, a partir de entonces, a la acumulación de reservas internacionales. La reducción del endeudamiento público obedeció tanto a decisiones explícitas de política fiscal (menos financiamiento externo y mayor utilización de los crecientes mercados internos de capital) como a los programas que favorecieron a los países pobres altamente endeudados y a la renegociación de la deuda argentina.

Por su parte, la acumulación de reservas obedeció a la decisión explícita de acumular tanto los excedentes de la cuenta corriente — generados en su mayoría, como se vio, por los precios excepcionales de los productos básicos - como la avalancha de financiamiento externo. Esto último se refleja en el gráfico 8, en que se calcula la acumulación de reservas como proporción del PIB en seis de las siete economías más grandes de América Latina durante las tres fases de abundancia de financiamiento externo. Como puede apreciarse, Argentina introdujo tempranamente una política de acumulación de reservas - provenientes en este caso del superávit en cuenta corriente más que de la cuenta de capitales_- Todos los países incluidos en el gráfico, con excepción de México, intervinieron activamente en el mercado para acumular parte de los fondos que ingresaron durante la avalancha de financiamiento externo que tuvo lugar entre mediados de 2006 y $2007 .{ }^{8}$ Chile, Perú y en menor medida otros países también lo hicieron durante el primer semestre de 2008. Este "miedo a flotar" frente a la avalancha de

\footnotetext{
${ }^{8}$ En el caso de Chile, los cálculos incluyen el traspaso de recursos a los fondos de estabilización. Asimismo, el saldo de dichos fondos se sumó al monto de reservas internacionales para calcular los coeficientes de endeudamiento externo de este país.
}

GRÁFICO 7

América Latina: deuda externa bruta y neta de reservas internacionales (Tipo de cambio de 2000)

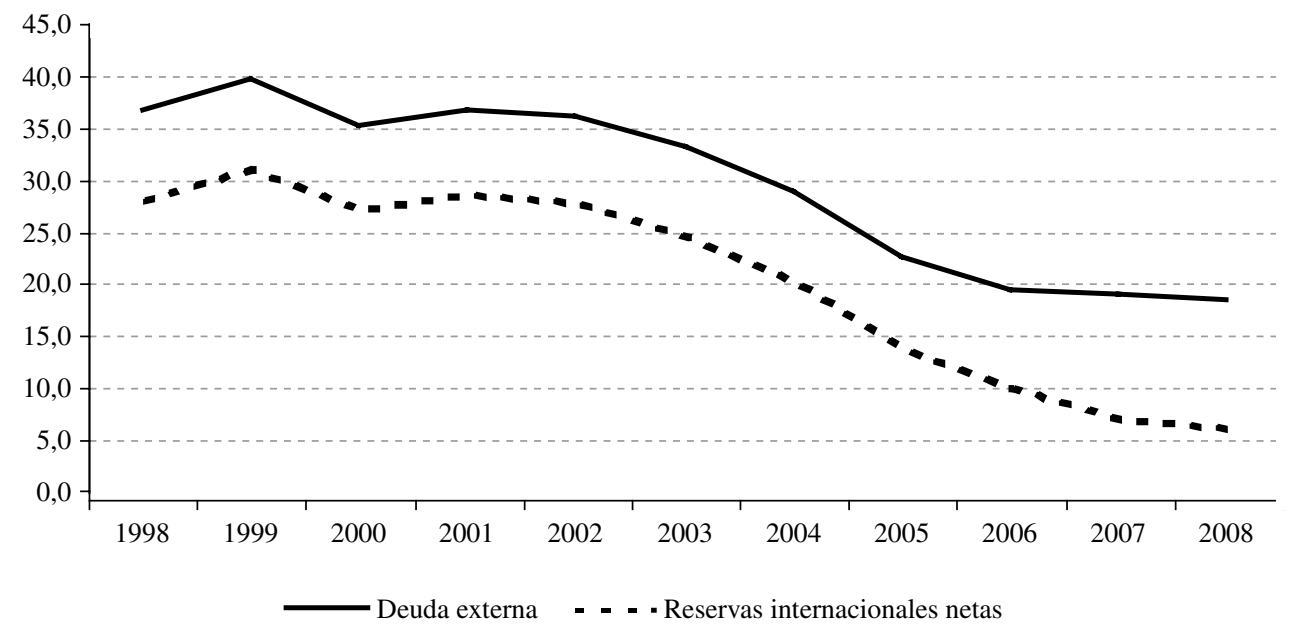

Fuente: elaboración propia sobre la base de datos de la Comisión Económica para América Latina y el Caribe (CEPAL). Nota: en el caso de Chile, incluye recursos de los fondos soberanos. 
GRÁFICO 8

América Latina (países seleccionados): reservas acumuladas en períodos de abundancia de financiamiento externo

(En porcentajes del PIB)

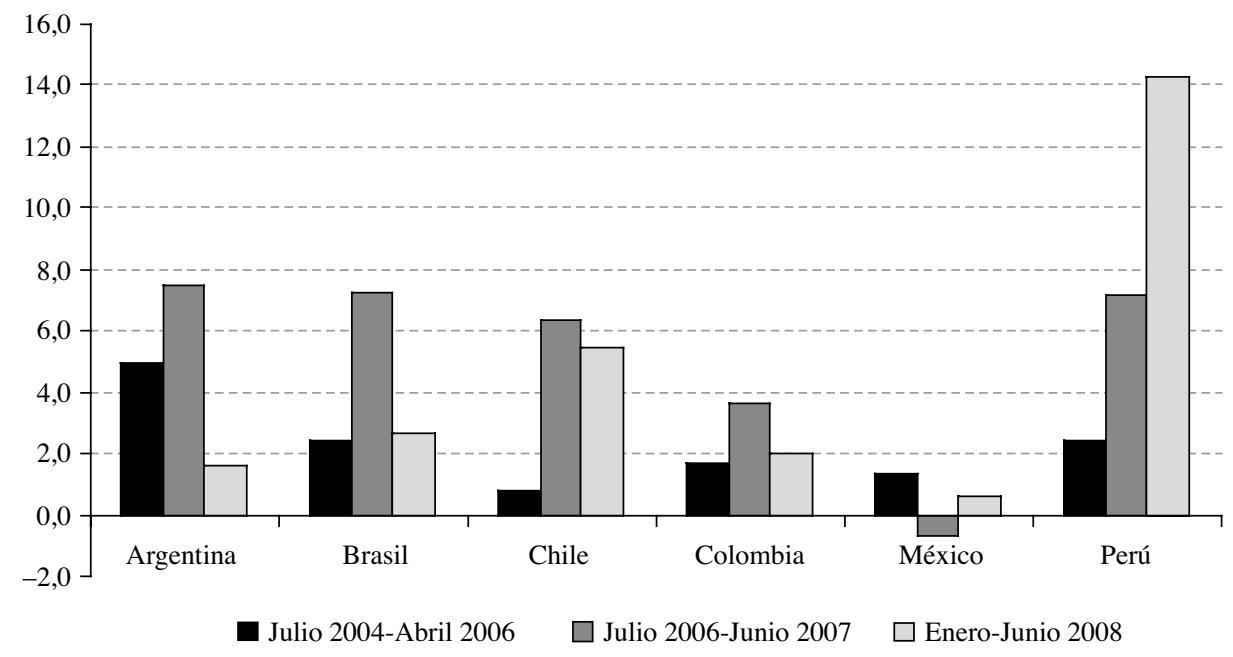

Fuente: elaboración propia sobre la base de datos del Fondo Monetario Internacional (FMI), Estadísticas financieras internacionales [en línea]. Nota: en el caso de Chile, incluye recursos trasladados a los fondos soberanos.

recursos externos de capital fue, por lo tanto, una de las grandes virtudes del manejo macroeconómico latinoamericano durante el período de auge económico reciente - como lo fue, de hecho, en el mundo en desarrollo en su conjunto-, aunque en algunos casos no sirvió para evitar la apreciación real de las monedas.

Como resultado tanto de la reducción del endeudamiento externo del sector público como de la acumulación de reservas, la situación de casi todos los países en esta materia es favorable (véase el cuadro 7). Las principales excepciones son algunos países centroamericanos (El Salvador, Nicaragua y Panamá) y, en menor medida, los países sudamericanos que heredaron una pesada carga de deuda externa de la crisis anterior (Argentina, Ecuador y Uruguay). Bolivia tiene una posición fuertemente superavitaria y en 2008 Brasil se encontraba en una situación de virtual equilibrio.

Esta situación favorable en materia de endeudamiento público y externo son los principales activos de la región frente a la crisis actual. En el primer caso, con algunas excepciones (Brasil y Colombia son las más evidentes), existe un margen más apreciable que en el pasado para adoptar políticas fiscales anticíclicas. Obviamente, el de Chile es mayor gracias al ahorro de un volumen importante de ingresos fiscales durante el período de auge económico. En varias economías, el volumen elevado de reservas internacionales se ha utilizado para mitigar los efectos de la crisis en los sectores exportadores y las empresas privadas sin acceso a financiamiento. Durante los meses más críticos de la crisis, permitió también aplicar algunas políticas de provisión de liquidez. Con posterioridad, los bancos centrales comenzaron a reducir sus tasas de intervención, una tendencia que ha tendido a generalizarse a comienzos de 2009. La presión sobre los tipos de cambio se dio en forma más acelerada que en el pasado y permitió corregir rápidamente la sobrevaluación existente en varias economías (Brasil, Chile, Colombia y México son los casos más destacados). A estas medidas se agregó un amplio abanico de políticas fiscales, sectoriales y sociales (CEPAL, 2009). Sin embargo, con excepción de la rápida depreciación de algunas monedas, hasta la fecha las repercusiones macroeconómicas de estas iniciativas han sido moderadas. 


\section{V}

\section{Conclusiones}

La crisis internacional ha tenido los efectos previstos en América Latina. El auge económico sustentado en una combinación excepcional de condiciones externas favorables se detuvo y todos los factores que lo nutrieron están operando ahora en sentido inverso. De ellos, la posible disminución de las remesas es el menos importante y en varios países se compensará mediante la devaluación real de las monedas, que afectará positivamente la capacidad de consumo interno de los hogares receptores de dichos recursos.

Las repercusiones más importantes y generalizadas de la crisis se apreciarán en el ámbito comercial. Todos los países, pero especialmente México, Centroamérica y el Caribe, están siendo afectados por la contracción del volumen real de comercio, mientras que las economías sudamericanas, sobre todo las exportadoras de productos mineros y energéticos, han experimentado un fuerte deterioro de los términos de intercambio. La caída de los precios de los productos energéticos compensará en parte los efectos adversos de la reducción del comercio internacional en varias economías pequeñas.

Desde el punto de vista del financiamiento externo, es posible que se hayan superado los problemas más agudos vinculados a la falta de liquidez que caracterizó la etapa más severa de la crisis (entre mediados de septiembre y fines de octubre de 2008). Sin embargo, queda por delante una fase de financiamiento externo privado muy restringido, cuya duración e intensidad se desconocen. El financiamiento multilateral solo podrá compensar en parte la escasez de fondos privados, salvo que se acompañe de medidas tales como una emisión excepcional y a gran escala de derechos especiales de giro por parte del FMI. Las ventajas de este financiamiento dependerán también de los requisitos vinculados al uso de los recursos del Fondo, un tema sobre el cual ha habido algunos avances, aunque incompletos. La falta de financiamiento privado afectará especialmente a algunas grandes empresas privadas, cuyas necesidades de rotación de las deudas son evidentes.

Las economías latinoamericanas llegan a la crisis con mayores fortalezas que en el pasado, pero ellas son más modestas de lo que se ha subrayado en algunos estudios optimistas sobre la gestión del auge económico reciente. Salvo excepciones notorias, entre las que destaca Chile, las políticas fiscales siguieron siendo procíclicas. Además, en la mayoría de los países hubo una tendencia al deterioro de la cuenta corriente, alimentada en muchos de ellos por la revaluación de las monedas. La reducción del endeudamiento externo del sector público y la decisión de absorber la avalancha de financiamiento externo mediante la acumulación de reservas son los dos elementos fundamentales de fortaleza, así como de ruptura con la forma de manejar las bonanzas económicas en el pasado. Todavía se desconoce cuál es el margen real que ellos ofrecen para adoptar políticas macroeconómicas anticíclicas durante la crisis que se inicia. Hasta ahora, el único aspecto destacable ha sido la rápida corrección de la fuerte sobrevaluación de algunas monedas en la región.

Las crisis del pasado indican que la depreciación real de las monedas representa una oportunidad para diversificar la estructura productiva. Es posible que esta sea la más importante que ofrece la coyuntura actual y, por lo tanto, debería apoyarse activamente mediante la aplicación de políticas de desarrollo productivo.

Los mercados regionales ofrecen también una oportunidad de diversificación, en cierto sentido de "sustitución de importaciones" en la región en su conjunto y no en países individuales. Sin embargo, las oportunidades de este tipo dependen de otros factores. De hecho, en las últimas décadas el comercio intrarregional ha sido fuertemente procíclico y los procesos de integración se encuentran en un momento de debilidad o incluso de crisis. Más aún, las grandes diferencias en materia de ajustes del tipo de cambio en el marco de los actuales acuerdos de integración y las medidas de protección individuales podrían contribuir más bien a ahondar las dificultades por las que atraviesan dichos procesos.

A diferencia del pasado, existen márgenes más amplios para aplicar políticas anticíclicas fiscales y monetarias que ya han comenzado a utilizarse en forma moderada, pero dichos espacios son limitados. Sin duda, evitarán la necesidad de adoptar políticas demasiado restrictivas, excepto en algunos países cuyo manejo del período de auge económico fue marcadamente procíclico. En síntesis, América Latina está mejor preparada que en otras ocasiones, pero ello solo servirá para mitigar en parte los efectos de la peor coyuntura que haya experimentado la economía mundial desde la gran depresión. 


\section{Bibliografía}

Banco Mundial (2009), Global Economic Prospects 2009: Commodities at the Crossroads, Washington, D.C.

BID (Banco Interamericano de Desarrollo) (2008), All That Glitters May Not Be Gold: Assessing Latin America's Recent Macroeconomic Performance, Washington, D.C., Departamento de Investigaciones, abril.

Bordo, Michael y otros (2001), "Is the crisis problem growing more severe?", Economic Policy, vol. 16, №32, Oxford, Blackwell Publishing, abril.

Bustillo, Inés y Helvia Velloso (2009), "The global financial crisis: what happened and what's next", Washington, D.C., Oficina de la CEPAL en Washington, D.C., enero.

Calvo, Guillermo (2008), "La super-crisis subprime: claves para entenderla y navegarla", presentación en el taller de la Corporación Andina de Fomento sobre "La crisis financiera global y su impacto en América Latina", Caracas, $1^{\circ}$ de diciembre.

CEPAL (Comisión Económica para América Latina y el Caribe) (2009), La reacción de los gobiernos de América Latina y el Caribe frente a la crisis internacional: una presentación sintética de las medidas de política anunciadas hasta el 30 de enero de 2009, Santiago de Chile, 30 de enero.

(2008a), La transformación productiva 20 años después: viejos problemas, nuevas oportunidades (LC/G.2367(SES.32/3)), Santiago de Chile.

(2008b), Estudio económico de América Latina y el Caribe, 2007-2008, Santiago de Chile. Publicación de las Naciones Unidas, $\mathrm{N}^{\mathbf{0}}$ de venta: S.08.II.G.2.

(2008c), Balance preliminar de las economías de América Latina y el Caribe 2008 (LC/G.2401-P), Santiago de Chile. Publicación de las Naciones Unidas, $\mathrm{N}^{\circ}$ de venta: S.08. II.G.2.

FMI (Fondo Monetario Internacional) (2009), World Economic Outlook Update [en línea] http://www.imf.org, 28 de enero.

IFI (Instituto de Finanzas Internacionales) (2009), "Capital flows to emerging market economies" [en línea] http://www.iif.com, 27 de enero.

Izquierdo, Alejandro, Randall Romero y Ernesto Talvi (2008), "Business Cycles in Latin America: The Role of External Factors", Washington, D.C., Banco Interameriano de Desarrollo/ CERES, febrero.
Jara, Alejandro y Camilo E. Tovar (2008), "Monetary and financial stability implications of capital flows in Latin America and the Caribbean", BIS Papers, $\mathrm{N}^{\circ}$ 43, Basilea, Banco de Pagos Internacionales, noviembre.

Jiménez, Juan Pablo y Varinia Tromben (2006), "Política fiscal y bonanza: impacto del aumento de los precios de los productos no renovables en América Latina y el Caribe", Revista de la CEPAL, No $^{\circ} 0$ (LC/G.2323-P), Santiago de Chile, diciembre.

J.P. Morgan (2009), Emerging Markets Outlook and Strategy, 12 de enero.

(2008), "Determinants of Mexico's remittances from the U.S.", Global Data Watch, 17 de octubre.

Kindleberger, Charles P. y Robert Aliber (2005), Manias, Panics, and Crashes: A History of Financial Crises, Nueva York, John Wiley and Sons.

Minsky, Hyman P. (1982), "The financial instability hypothesis: a restatement", Can "It" Happen Again? Essays on Instability and Finance, Armonk, Nueva York, M.E. Sharpe.

Naciones Unidas (2009), World Economic Situation and Prospects 2009, Nueva York, enero.

Ocampo, José Antonio (2007), "La macroeconomía de la bonanza económica latinoamericana", Revista de la CEPAL, $\mathrm{N}^{\circ} 93$ (LC/G.2347-P), Santiago de Chile, diciembre.

Ocampo, José Antonio y María Ángela Parra (2003), "Los términos de intercambio de los productos básicos en el siglo XX", Revista de la CEPAL, $\mathrm{N}^{\circ} 79$ (LC/G.2200-P), Santiago de Chile, abril.

Ocampo, José Antonio y Camilo E. Tovar (2008), "External and domestic financing in Latin America: developments, sustainability and financial stability implications", documento presentado en el taller realizado en las Naciones Unidas sobre "Debt finance and emerging issues in financial integration", Nueva York, abril.

Ratha, Dilip, Sanket Mohapatra y Zhimei Xu (2008), "Outlook for remittance flows 2008-2010: growth expected to moderate significantly, but flows to remain resilient", Migration and Development Brief, № 8, Washington, D.C., Banco Mundial, 11 de noviembre.

Von Braun, Joachim (2007), "The world food situation: new driving forces and required actions", Food Policy Report, Washington, D.C., Instituto Internacional de Investigaciones sobre Políticas Alimentarias, diciembre. 